Florida International University FIU Digital Commons

10-26-1992

\title{
The effect of sexist attitudes on the perception of visual artists by community college and university students
}

Kyra Belan

Florida International University

DOI: $10.25148 /$ etd.FI14050480

Follow this and additional works at: https://digitalcommons.fiu.edu/etd

Part of the Higher Education Commons

\section{Recommended Citation}

Belan, Kyra, "The effect of sexist attitudes on the perception of visual artists by community college and university students" (1992). FIU Electronic Theses and Dissertations. 1507.

https://digitalcommons.fiu.edu/etd/1507 
ABSTRACT OF THE DISSERTATION

The Effect of Sexist Attitudes on the Perception of Visual Artists by Community College and University Students

by

Kyra Belan

Florida International University, 1992

\author{
Miami, Florida \\ Professor Joseph B. Cook, Major Professor
}

This study compared the effects of sexist labeling on the perceptions of visual artists by the community college and university students and determined their sex role orientation.

The 370 students were shown five slides of an artist's works and were given six versions of an artist's biography. It contained embedded sexual labeling (woman, girl, person/ she, man, guy, person/he). The Artist Evaluation Questionnaire was administered to the female and male community college and university students that required the students to evaluate the female and male artists on several aspects of affective and cognitive measures. The questionnaire consisted of 9 items that had to be rated by the participants. In addition, the students filled out the Demographic Questionnaire and the BEM Sex Role Inventory, 
titled the Attitude Questionnaire. The Analysis of Variance testing procedures were administered to analyze the responses.

The results disclosed gender differences in students' ratings. The female artist's work, when the artist was referred to by the neutral sexual label, "person", received significantly higher ratings from the female students. The male students gave the female artist her highest ratings when she was referred to by the low status sexual label, "girl". Both sexes did not express statistically significant preferences for any of the male sexual labels.

Gender difference became apparent when it was found that female students rated both sexes equally, and their ratings were lower than those of the male students. The male students rated the female artist's work higher than the work of the male artist.

The analysis of the sex role inventory questionnaire revealed the absence of the feminine (expressive) and masculine (instrumental) personalities among the students. The personalities of almost all the students were androgynous, with a few within the range of the near feminine, and a few within the range of the near masculine. The study reveals that there are differences in perception of sexual labels among the community college and university students. 
FLORIDA INTERNATIONAL UNIVERSITY

Miami, Florida

The Effect of Sexist Attitudes on the Perception of Visual Artists by Community College and University Students

A dissertation submitted in partial satisfaction of the requirements for the degree of Doctor of Education in Community College Teaching

by

Kyra Belan 
(C) Copyright by Kyra Belan 1992 
To Professors: Joseph B. Cook

Hugh Gladwin

Clement Pennington

James W. Couper, III

This dissertation, having been approved in respect to form and mechanical execution, is referred to you for judgment upon its submitted merit.

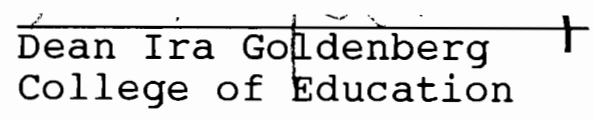

The dissertation of Kyra Belan is approved.

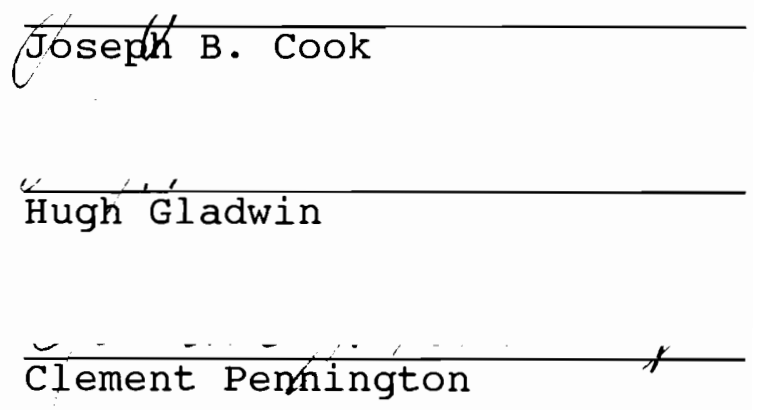

Date of Examination:

October 26, 1992

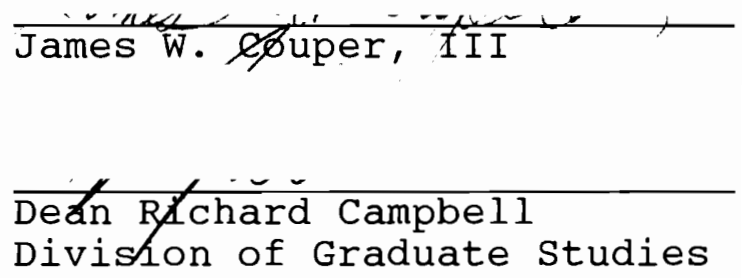

Florida International University, 1992 
To Charles Martin

iii 


\section{ACKNOWLEDGMENTS}

I would like to express my gratitude to my major professor, Joseph B. Cook, who inspired and guided me through the coursework and this dissertation, my professor Hugh Gladwin, whose advice and guidance during the completion of this work was critical to its success, and my professors Clem Pennington and James Couper, who were there when I needed them. I am very thankful to Betty Owen, who took time to edit this work, and to Nancy Firestone for giving me moral support. My sincere thanks to Abe Biggs, Vicki Hendricks, Chuck Eisman, Pat Ellingham, E. Joseph Kaplan and Susan Emery Eisenberg for their assistance or advise. 
1973 B.F.A.

1975 M.F.A.

$1974-75$

1976

1977

$1982-84$

$1982-84$

1984-present

1990-present
Fine Arts

Arizona State University

Tempe, AZ

Visual Arts

Florida State University

Tallahassee, FL

Teaching Assistant

Florida State University

Instructor

Broward Community College

Coconut Creek, FL

Initiated Art Department

Broward Community College

Pembroke Pines, FL

Department Chair, Humanities Broward Community College Pembroke Pines, FL

Gallery Director

Broward Community College Davie, FL

Coordinator, Art Department Broward Community College Pembroke Pines, FL

Galley Director

Broward Community College

\section{PUBLICATIONS AND PRESENTATIONS}

Honors, Awards and Grants (selected)

Who's who in American Art, 20th Edition, 1993-94

Who's who in American Art, 19th Edition, 1992

Who's Who of American Women, 15th edition, 1987-88

Who's Who in American Art, 17 th edition, 1986

Money for Women - Barbara Deming Memorial Fund Grant, for the Magic Circle Goddess Series, 1986

Metro-Dade Art in Public Places Commission, Miami, FL, 1986. 
Who's who in the South and Southwest, 1985/86

Who's who in America, 1985

Who's who in the South and Southwest, $1984 / 85$.

Individual Artist Fellowship, State of Florida, Florida Fine Arts Council, 1982

Mayor David Keating Award, Greater Hollywood Creates 1981, Art and Culture Center of Hollywood, Hollywood, FL, 1981

Broward Art in Public Places, Commission for Southern

Regional Courthouse, Hollywood, FL, 1981

Outstanding Artist of the Southeast, American Art/Southeast Magazine, 1978

Best of Show Award, Best of Womanart, Anniversary

Exhibition, Womanart Gallery, New York, NY, 1977

\section{One Artist Exhibitions (selected)}

Our Lady of Florida: Magic Circle Xx, The Art Gallery, Broward Community College, Pembroke Pines, FL, 1991

Great Goddess Chalchiutlicue: Magic Circle XVIII, The Rim Institute, Payson, AZ, 1989

Cosmic Goddess Chicomecoatl/Demeter: Magic Circle XV, Dupont Gallery, Washington and Lee University, Lexington, VA, 1988

Great Goddess Chicomecoatl: Magic Circle XIV, Art and Culture Center of Hollywood, Hollywood, FL, 1987

Nature Goddess Sekhmet: Magic Circle XII, Miami Site, Key Biscayne, FL, 1987

The Magic Circle Series 1978-1985, Einstein Library, Nova University, Davie, FL, 1985

Great American Indian Goddess Coatlicue: Magic Circle VIII, Fine Arts Gallery, Broward Community College, Davie, FL, 1984

Goddess Isis: Magic Circle VII, New World Campus, MiamiDade Community college, Miami, FL, 1984

\section{Books and Exhibition Catalogs (Selected)}

Orenstein, Gloria. (1990). The reflowering of the goddess. Pergamon Press.

Wynne, P. (Ed.) (1988). The womanspirit sourcebook.

Expressions! The 6th Annual Competition and Exhibition. (1986-87). Art and Culture Center of Hollywood. Juror: Judy Chicago.

Third Annual Miami Waves Experimental Film and Video Forum. (1984). Miami, FL: Miami-Dade Community College. 
Tufts, E. (1984). American Women Artists. Garland Publishing.

Florida Visual Artists, 1982-1983. (1983). Florida Department of State, Fellowship Catalogue, George Firestone, Secretary of State.

24th Annual M. Allen Hortt Memorial Exhibition. (1982). Fort Lauderdale, FL: The Museum of Art.

Women's Vision. American Artists of Renown, 1981-1982.

(1981). Gilmer, TX: Wilson Publishing Co.

Southern Exposure: Women Artists in the South. (1980). Juror: Dorothy Gillespie. New Orleans, LA: Hanson Gallery. (Foreword: Donald B. Kuspid).

Kyra. (1980, September 9-October 10) Magic Florida. Hollywood, FL: Art and Culture Center of Hollywood.

Contemporary Reflections of the 19th Century/South Florida Women. (1979). Outstanding young women of America. Biographical work compilation, Montgomery, AL.

Best of Womanart 1977. Jured: New York: Womanart Gallery.

\section{Articles and Reviews in Magazines (selected)}

Lauter, E. (1900). Women as mythmakers revisited. Quadrant, XXIII, 1 .

Kyra. (1988, Spring). Art and profile. The New Renaissance, $\underline{22}$.

Kyra. (1987). Goddess images, myths, and symbols in the art of women of the southeast. Southeastern College Art Conference Review, $\underline{\text { XI. }}$

Kyra. (1987, Spring). The magic circle series. Woman of Power, $\underline{6}$.

Gildar, L. (1983). Male nude: The image is the issue. Hue Points, 12 .

Comini, A. (1983). The hierarchy in art history: Has it changed after a decade of ferment? Women Artists News, $\underline{8}$. 
Comini, A. (1980). Titles can be troublesome: Misinterpretations in male art criticism. Art Criticism, $\underline{1}$.

Springer, M. (1978). Southeastern artists: A cross section. Contemporary Art/Southeast, $\underline{2}$.

\section{Papers (selected)}

The Shamanic Journey: Magic Circle Goddess Series (The Art of Kyra). Paper, The thirteenth International Conference on the Fantastic in the Arts, Dania, March 26, 1992.

Art and Sexist Attitudes: Double standard is Alive and Well in Higher Education. Paper, College Art Association 80th Annual Conference, February 13, 1992.

The Great Goddess Archetype in the Works of Women Artists in the Twentieth Century. Paper, Southeastern College Art Conference, The Atlanta College of Art, Atlanta, October 26,1990 .

Magic Circle Goddess Series: A Tribute to Female Spiritual Power. Paper, Southeastern College Art Conference, 1989, Little Rock, October 27, 1989.

The Diakosmos of Core, Demeter and Persephone: A Drama of Life, Death and Resurrection. Paper, The International Association of the Fantastic in the Arts 10th Annual Conference, Dania, March 17, 1989.

Male Nude: A Female point of View. Paper, Southeastern College Art Conference, 1986 Annual Meeting, University of Alabama, Tuscaloosa, October 31, 1986.

Goddess Power and Revival of Feminist Mythology. Paper, Southeastern College Art Association 1986 Annual Meeting, University of Alabama, Tuscaloosa, October 30, 1986. 
TABLE OF CONTENTS

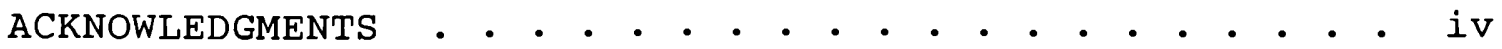

LIST OF TABLES . . . . . . . . . . . . . . . . . . . $\mathrm{xi}$

Chapter

I. Introduction . . . . . . . . . . . . . . . 1

Background of the Study Problem . . . . . . 1

Need for and Purpose of the Study . . . . . 7

Significance . . . . . . . . . . . . . . 7

Hypotheses . . . . . . . . . . . . . . 9

Definition of Terms . . . . . . . . . . 10

Summary .................. 11

II. Review of Literature . . . . . . . . . 13

Introduction . . . . . . . . . . . . . . . 13

Sexism and the Development of Art History

as a Discipline . . . . . . . . . . . . 14

Educational System and Gender Attitudes . . . 28

Sexism in Textbooks . . . . . . . . . . . 30

Perception of Sex Roles by College Students . 34

Sexist Language and Discourse in Higher

Education . . . . . . . . . . . . . . 41

Summary .. . . . . . . . . . . . . 49

III. Methodology . . . . . . . . . . . 50

Research Method . . . . . . . . . 50

Population . . . . . . . . . . . . . 50

Sample . . . . . . . . . . . . . . 51

Instruments . . . . . . . . . . . . 55

Procedure . . . . . . . . . . . . . 59

Assumptions . . . . . . . . . . . . . . 61

Limitations . . . . . . . . . . . . . 61

Assurance ... . . . . . . . . . . 62

Summary .................. 62

IV. Analysis of Data and Results . . . . . . . 64

Definition of Variables . . . . . . . 64

Analysis of Data................ . . 65

Summary . . . . . . . . . . . . . . 95 
v. Summary, Conclusions and Recommendations . . 98

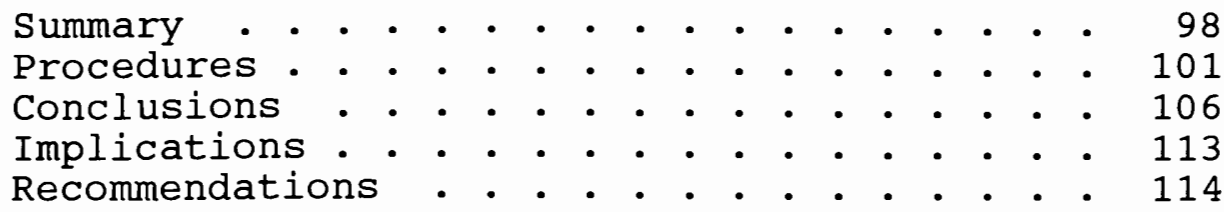

REFERENCES . . . . . . . . . . . . . . . . 116

APPENDICES . . . . . . . . . . . . . . . 123

A. LETTER TO FACULTY . . . . . . . . . . . . . 123

B. FACULTY INSTRUCTIONS . . . . . . . . . . . . . 125

C. LETTER TO STUDENT . . . . . . . . . . . . . . 127

D. INSTRUCTIONS . . . . . . . . . . . . . . . . . . 129

E. ARTIST'S BIOGRAPHY SKETCH . . . . . . . . . . . 131

F. ARTIST EVALUATION QUESTIONNAIRE . . . . . . . . 133

G. DEMOGRAPHIC QUESTIONNAIRE . . . . . . . . . . . 136

H. ATTITUDE QUESTIONNAIRE . . . . . . . . . . . . 139 
Table

1. Ethnicity of Students Participating in the Study . . . . . . . . . . . . 53

2. Years of College Completed of Students Participating in the study . . . . . . 54

3. Type of Degree of Students Participating in the study . . . . . . . . . . 55

4. Age of the Participating Students . . . . 56

5. Responses of Female and Male Students to the Artist Evaluation Questionnaire Rating Gender of Artist . . . . . . . . . 67

6. Responses of Female Students to the Artist Evaluation Questionnaire Rating Gender of Artist . . . . . . . . . . . . . .

7. Responses of Male Students to the Artist Evaluation Questionnaire Rating Gender of Artist . . . . . . . . . . . . 70

8. Responses of Female and Male Students to the Artist Evaluation Questionnaire Rating Female Sexual Labels . . . . . . . .

9. Responses of Female Students to the Artist Evaluation Questionnaire Rating Female Sexual Labels . . . . . . . . . 76

10. Responses of Male Students to the Artist Evaluation Questionnaire Rating Female Sexual Labels . . . . . . . . . . .

11. Responses of Female and Male Students to the Artist Evaluation Questionnaire Rating Male Sexual Labels . . . . . . . . .

12. Responses of Female Students to the Artist Evaluation Questionnaire Rating Male Sexual Labels... . . . . . . . . .

13. Responses of Male Students to the Artist Evaluation Questionnaire Rating Male Sexual Labels. 
14. Female and Male (All Students) Androgyny Score for Artist Evaluation Questionnaire . $\quad 89$

15. Female Students Androgyny Score for the Artist Evaluation Questionnaire Ratings . • 91

16. Male Students Androgyny Score for the Artist Evaluation Questionnaire Ratings . . 92

17. Summary of Findings . . . . . . . . . . 96 
CHAPTER I

Introduction

\section{Background of the Study Problem}

The discipline of art history, as presented to college and university students within the present academic structure, reflects the same patriarchal bias toward the female gender as the rest of the higher education curricula. Many inroads have been made to remedy the situation. However, these efforts are at an embryonic stage at this time. New art historical research is taking place on the previously unresearched contributions of women artists through history, and efforts are being made to present this discipline within its sociocultural environment, in order to explain the power structure that condoned the suppression and omission of the female gender from previous art historical research.

Artistic expression, which is manifested in the art object, either material or conceptual, is a form of human communication. In order to be understood, the art object must be examined in the context of the particular cultural structure that produced it. The history of human artistic achievement is best comprehended and analyzed in the context of the specific social structure that had generated the artists that produced it. The content, form, and style of 
an art object correlate to the sociocultural environment that engendered that art object. In fact, the ichnography, the symbolism, the function and the style of an art object are defined by numerous cultural factors.

The art object, and its creator, the artist, are perceived by a particular culture through the filter of this culture's value system, ideology, religion, mythology, and the symbology of a particular language used by that culture. The symbology of a language includes various social designations, including that of gender. The investigation of the perception of the gender of the artist in present society constitutes the focal point of this study.

Although there is recent evidence of attempts on the part of contemporary art historians to examine the cultural contexts in which the artists produce their art objects, archeologists, according to otten (1971), had exhibited interest in "the study of cultures as human value-systems" (p. xi) earlier in the twentieth century. Otten also notes that after archeologist Ernest Grousse introduced "the question of a functional relationship between art and culture" (p. xi) in 1894, subsequent research into a correlation of social structures with art purposes and styles was not attempted until the decade of the 1960s. Since, numerous archeologists have attempted to redefine art in terms of its sociocultural background. Sieber (1971) believes that: 
In order to discuss the changing function of art it is first necessary to posit a definition of art that can include the concept of social function as an essential aspect. Only then will it be possible to examine, briefly and in general terms, the character of a few of the changes in the arts and their social functions. ( $p$. 203)

In order to understand the dynamics of art, artist and culture, the artificial boundaries between the individual disciplines of art history, education, archeology, and anthropology must be crossed. Consequently, a more complete picture of the dynamics between artist, art, and society can be perceived.

The current change in societal attitude that seems to be evolving toward a partnership model, is allowing a nonsexist approach to education to begin to emerge. This change is largely due to the scholarly research of early feminists, such as Simone de Beauvoir. According to de Beauvoir (1974), even "the most mediocre of males feels himself a demigod as compared with women" (p. xxviii) because as presented through patriarchal education, history almost totally belongs to men. In her germinal work, The Second Sex, de Beauvoir (1974) also explains that our society is conditioned to assume that all the new and important ideas are generated by men. The second major wave of feminism to sweep the world and the American colleges during the late 1960 s and early 1970 s felt inspired by the writing of Friedan (1983), who observed that college education heavily discriminated against women. Feminist 
Gould-Davis (1971) postulates that the contributions of the female gender to the development of human culture and civilization are as major, if not greater than those of the male sex.

While research that attempts to fill the gaps of previous omissions of women's accomplishments in the curricula of higher education is taking place, and some progress is being made in the area of art history, current art education is still very far behind the goal of equal education of both sexes. One area that crosses over into every single discipline is the study and the use of language. The language of the present patriarchal society is based on numerous sexist assumptions and attitudes and is the subject of analysis by the feminist scholars of every discipline, including the disciplines of art and art history. In response to this inequity, Daly (1984), perhaps the most radical of feminist philosophers, created much of her own non-sexist linguistic terminology. Daly suggests that in order to gain equality, women need to participate in the act of "Naming" or generating their own linguistic terms, definitions and rules, such as metabeing. She proceeds to assert that:

Metabeing conveys multiple meanings, since the prefix meta has several senses. First, it means 'occurring later.' This aspect is important since, under patriarchal conditions, knowledge as participation in Elemental Powers of Be-ing is experienced as an existential breakthrough after a woman has understood that the blockage of her powers within phallocracy, that is, the reduction of these to mere things/beings, 
is insufferable. The second meaning of meta, which is 'situated behind,' is also essential, for Lusty women's discovering of our be-ing are not experienced as entirely new. In breaking through the man-made reifications of Being, women enter Realms of our ancestral memories. These memories can move women out of the passive state of things/nouns, out off from our own be-ing. (p. 27)

It is obvious that this society is going through a change in the roles of the genders. These sex roles were assumed to be fixed by the patriarchal philosophy and backed by patriarchal religious and political structures. However, most progressive thinkers of our time are aware that human social structures, to which educational structures conform, are not fixed, but rather are in a state of flux. One of the most respected authorities in education, Campbell (1972), declared the following:

Our ideal for a society, in other words, is not that it should be a perfectly static organization, founded in the age of the ancestors and to remain unchanging through all time. It is rather of a process moving toward a fulfillment of as yet unrealized possibilities; and in this living process each is to be an initiating yet cooperating center. We have, consequently, the comparatively complex problem in educating our young of training them not simply to assume uncritically the patterns of the past, but to recognize and cultivate their own creative possibilities; not to remain on some proven level of earlier biology or sociology, but to represent a movement of the species forward. (p. 47)

Eisler (1987) predicts that our current societal structure, the dominator model, is evolving and will, perhaps, take a form that will develop into a new partnership model. This new social construct may even reposition the two sexes into a balance of power. She feels 
that this direction is necessary in order to save the dominator model society from self-destruction, since the balance of the sexes would bring with it the ecological consciousness and peaceful attitude toward others. However, the author points out that, at this time, the dominator model of society, a male construct, is still being internalized as follows:

The two basic human types are male and female. The way the relationship between women and men is structured is thus a basic model for human relations. Consequently, a dominator-dominated way of relating to other human beings is internalized from birth by every child brought up in a traditional, male-dominated society. (p. 168)

By the time these human beings reach college level, they have firmly internalized the dominator model of society, and colleges have done very little to introduce a non-sexist approach to teaching. One area of education that displays multiple sexist problems in its educational agenda is the discipline of art history. Before the seventies, great women artists were excluded from the art history textbooks, such as History of Art by Janson (1971). Female artists were usually absent from campus galleries and museums, and female professors were almost non-existent. While today, this sexist treatment of the female gender is somewhat improved, the gap between the male and the female representation in college texts and art collections is still vast. The scarcity of female tenured faculty is also 
evident, as well as the frequent discriminatory practices, which often include the use of sexist language.

\section{Need for and Purpose of the Study}

It was evident that there was a substantial difference between the education of male and female students, and it was necessary to examine this difference by designing a study that would attempt to determine the impact of the present higher education curricula on the perception of the female and male college and university students. The purpose of this study was to investigate and determine whether community college and university students displayed sexist behaviors in affective and cognitive domains when perceiving works of art by female and male artists, and whether sexual labels, attached to the artists, determined the affective and cognitive perceptions of these students.

\section{$\underline{\text { Significance }}$}

Although there is evidence of awareness among art historians and art educators of colleges and universities that there is a significant difference between the treatment of the genders in art and art history, there are only two studies discovered after an extensive review of literature, that attempt to deal with the issue. The first study by Pheterson, Kiesler, and Goldberg (1971), using women as subjects, demonstrated that subjects judged an assumed 
female artist's work as significantly lower than the assumed male artist's work.

The second study, conducted by Lipton and Hershaft (1984), investigated the effect of sexist labeling on 60 male and 60 female college level students. The results of this study indicated that both the high status label (woman) and the low status label (girl) had negative effects on the subjects' judgments of the female artist; for the male artist, both the high status label (man) and the low status label (guy) had equally positive effects on the subjects' judgments. The neutral label (person) had a more positive effect on the subjects' judgments of the female artist's work. In fact, when referred to as a "person", the female artist was rated as high as the male artist. This study did not find any significant differences between the judgments of the female and male subjects.

While during the last nine years preceding the present study, some improvement in the treatment and perception of women in art history and art curricula of higher education did occur, there were still significant differences in favor of the male artists in all art related fields, including textbooks. There was a need to find out how these differences affected the cognitive and affective perceptions and judgments of college level students in regard to the gender of the artist, whether these perceptions were affected by the use of sexist language; whether these 
perceptions would vary because of the gender of the subjects; and whether the subjects' sex role orientation, as determined by the Bem Sex Role Inventory (BSRI) (Bem, 1981) questionnaire, would impact their judgments. The results of this study would be used for further research and as a guide to predict which areas of sexism in education would need to be eliminated or modified.

\section{Hypotheses}

The null hypotheses that were tested in this study are the following:

1. There are no statistically significant differences in perception of a female or male artist's work by community college and university students.

2. There are no statistically significant differences in perception of a female or male artist's work between female and male community college and university students.

3. There are no statistically significant differences in perception of a female artist's work, when referred to as "woman," "girl," or "person," by female and male community college and university students.

4. There are no statistically significant differences in perception of a female artist's work, when referred to as "woman," "girl," or "person," between female and male community college and university students.

5. There are no statistically significant differences in perception of a male artist's work, when referred to as 
"man," "guy," or "person," by female and male community college and university students.

6. There are no statistically significant differences in perception of a male artist's work, when referred to as "man," "guy," or "person," between female and male community college and university students.

7. There are no statistically significant differences in perception of a female and male artist's work between expressive (feminine), instrumental (masculine) or androgynous personalities of community college and university students.

8. There are no statistically significant differences in perception of a female and male artist's work between expressive (feminine), instrumental (masculine), or androgynous personalities female community college students and between expressive (feminine), instrumental (masculine) or androgynous personalities of male community college and university students.

\section{Definition of Terms}

The following terms are defined for the purpose of this study:

AFFECTIVE: Caused by or expressing emotion or feeling. BEM SEX ROLE INVENTORY (BSRI) (Bem, 1981): Developed to provide construct validation for the concepts of expressive (feminine), instrumental (masculine), and 
androgynous personalities; it measures personality traits and behavior patterns related to sex roles.

COGNITIVE: Pertaining to the mental processes of perception, memory, judgement and reasoning.

INSTRUMENTAL: Serving or acting as an instrument or means; being useful or helpful.

MATRIARCHY: A family or society governed by women, or a society where women have the right to give their name, title, or property to their children.

MATRIFOCAL: Pertaining to a family unit that is headed by the mother.

MATRILINEAR: A society that is based upon descent through the female line.

MATRILOCAL: A family unit that is centered on the residence of a wife's mother's family.

PERCEPTION: A single unified awareness derived from sensory processes while a stimulus is present.

SEXISM: Attitudes or behaviors based on traditional sexual roles; discrimination or prejudice based on a person's sex, usually referring to discrimination against women. 


\section{$\underline{\text { Summary }}$}

The purpose of this study was to determine whether community college students and university students displayed sexist behaviors and judgments in affective and cognitive domains when perceiving works of art by female and male artists, and whether sexual labels, attached to the female and male artists, determined the affective and cognitive perceptions of these students. 
CHAPTER II

Review of Literature

\section{Introduction}

It is the researcher's belief that all educational research must take place within the scope of its sociocultural context in order to present a more comprehensive and complete study construct. Therefore, the nature of this interdisciplinary study extended into the areas of higher education, visual art and art history, and social science. This research outlined the sociocultural background against which the present system of higher education developed, and it determined the current educational environment and attitudes that the college student population of the decade of the nineties exhibits toward the female gender. The relevant literature includes the highlights of the art history, the history of gender bias within our sociocultural environment, and the construct of the current educational system. Perhaps the most important controlling factor in the perpetuation of the gender bias that currently exists in society and the higher education system is the use of sexist language. This paramount component of the present cultural environment also was explored in this literature review. 


\section{Sexism and the Development of Art}

History as a Discipline

At the dawn of our civilization, art was perceived as one with religion. The oldest art object of Prehistoric era that has been discovered is a small sculpture in the round of the Great Mother Goddess, usually identified as the Goddess of Willendorf and dated around 35,000 B.C.E. This Goddess figure symbolically embodied in herself the social structure that existed at that time, when the female half of the human race was perceived as the dominant gender, or as the first sex. Due to recent extensive research by numerous archeologists, including Gimbutas (1989), we have become aware that between 35,000 B.C.E. and 5,000 B.C.E., the structure of societies of the Prehistoric civilizations was based on the assumption that woman rather than man was best suited to represent the deity, which was visualized and perceived as omnipotent Mother God. This female God appropriately represented a matriarchal society. The artists-priests of this matriarchy were women like her, and it is safe to assume that the role of a woman as artistshaman was perceived as appropriate for an individual of female gender.

Thousands of years later, according to Stone (1976), Gimbutas (1983, 1989, 1991), Walker (1985) and other feminist researchers, the Neolithic agricultural civilization continued to develop its matriarchal structure, maintaining matriarchal rights of property transfer from 
mother to daughter. The female priesthood continued to be interconnected with or involved in the artistic production of ritual objects. The development of the first scripts that adorn numerous goddess figures and ritual/utilitarian artworks, is also generally assumed to be generated by female hands.

This extensive, yet still infrequently studied part of human history was followed by a long struggle between the dominant matriarchal and the emerging patriarchal societal structure (Stone, 1976; Gimbutas, 1983, 1989, 1991; Broude \& Garrard, 1982; Walker, 1985; and others). Several sociocultural compromises took place in the various civilizations of the Ancient world, and the present patriarchal culture took shape over 2,500 years ago, with the last two millennia ruled by the strictly patriarchal structure. This current male dominant system still promulgates the view of the female gender as the second sex, and within this construct the women are usually relegated to powerless, silent and disencumbered positions. Therefore, the existence of female artistic creativity within a culture that denies female divinity and female rights is considered an aberration, an exception or a borrowed quality (since God is now of only male gender according to all the dominant religious systems). The history of the art of Western Civilization is the history of the Western white males' artistic accomplishments, while the art that was or is 
generated by the female artist is usually allowed to exist outside the mainstream of the history of art and is perceived as less valuable, less creative and of less consequence to the society as a whole.

The origins of the discipline of art history may be traced as far back as the beginning of the first century C.E., when Pliny the Elder first wrote his Historia Naturalis (Chadwick, 1990). In this book, Pliny's discussion of the history of the painting and sculpture of the world of antiquity, mentions several female painters, including Helene of Egypt. She painted The Battle of Issus which included both Alexander the Great and Darius. However, a later and more direct attempt at documentation of art was Vite de Pittori, Scultori e Architettori by Vasari (1550, 1558). Vasari traced the development of Renaissance art from the thirteenth through sixteenth centuries, and according to Chadwick (1990), mentioned at least 13 women artists. The list included such artists-painters as Sophonisba Anguissola, Lavinia Fontana and Elisabetta Sirani and sculptor Properzia De Rossi. Chadwick (1990) notes that the praise of women artists by Vasari was worded differently from those directed at their male counterparts, highlighting "diligence rather than invention" (p. 28).

Although women artists were appearing in art history texts of the seventeenth and eighteenth centuries, their inclusion was sporadic and inconsistent. Some women artists 
were dropped, while some new ones appeared, to only disappear out of sight from the next art history book. This disposable and token insertion of women artists into the patriarchal history of art, with minimal research and consideration, is typical of a patriarchal culture in general and still largely applies today.

Within this patriarchal system, women artists had great difficulty in obtaining the appropriate art training that was usually available to male artists. Their access to art education, particularly in nude figure drawing, painting and sculpting, was very limited during the Renaissance and later periods. During the Renaissance and Baroque periods, when it was absolutely essential to know human anatomy and the nude figure, female artists were traditionally forbidden to study the male nude. This fact successfully eliminated them from the numerous important commissions available to all the male artists. Harris and Nochlin (1976) and Slatkin (1985) point out that most women artists during those centuries did not try to compete with the better trained male artists for the most coveted and the best rewarded commissions, and were relegated to the less prestigious genres of portrait painting and still life. Slatkin (1985) also explains how crucial the access to education is to an artist by pointing out the difference in women's contributions to a specific field of artistic discipline. She states that the field of architecture was out of reach to most women artists due to 
lack of access to the appropriate training, and women's contributions as trend setters are very limited in this area. The art of photography was not immediately recognized as a valid form of art, and, therefore, both education and entry into this field was readily available to women. As a result, the contributions of women photographers as pioneers and innovators in this field are major since the invention of this medium in the nineteenth century (Slatkin, 1985).

It must, however, be remembered that the long lasting matriarchies of the Paleolithic, Neolithic, and Ancient eras originated the visual arts, such as sculpture, cave paintings (or, more correctly, drawings), ceramics and architecture. All those arts were initially at the service of the Great Mother God religion, whose female priesthood enacted rituals invented by themselves to convey messages through myths and symbols that it also generated (GouldDavis, 1971; Stone, 1976; Walker, 1983). The fact that the art of pottery making and the first forms of writing were invented by those women is currently acknowledged (Gimbutas, 1983, 1989, 1991), and numerous scholars agree that such matriarchal civilizations also produced women who invented the arts of sculpture and drawing/painting. Even the creation of ancient architecture is more frequently attributed to women by contemporary scholars, since numerous anthropological studies observed that in today's primal and non-western societies the duty of dwelling construction 
often falls on the females of the tribes. One such example is the matriarchal Apachean-speaking tribes of Arizona, sections of New Mexico, Colorado, Oklahoma and other territories throughout the United States.

Perhaps the most thorough investigation into the generation of symbols by the female artists of the Neolithic era, primarily as content to the form in their arts, may be found in the conclusive evidence presented in the texts of archeologist Gimbutas (1989, 1991). Gimbutas states that her primary purpose for writing her book, titled The Language of The Goddess, was to research the pictorial script of the religion of the old European Great Goddess, "consisting of signs, symbols, and images of divinities" ( $p$. $\mathrm{xv})$. The author stipulates that these are the primary sources for the reconstruction of the true historic heritage, and that this heritage of many thousands of years is imperative to correct the distorted understanding of religion and mythology of Western civilization. For over 20 years, Gimbutas $(1983,1989,1991)$ investigated the art objects, such as the sculpture and the pottery of Neolithic Europe, and concluded that these numerous images and symbols constituted a specific ideology of that time, and represented a form of metalanguage, by which complex meanings were transmitted.

Current investigations by the anthropologists confirm that beneath the dominant/patriarchal western culture, there 
are numerous matriarchal, matrilinear and matrifocal societal structures. These subcultures are scattered all over the globe, representing a powerful but little known cultural undercurrent. According to Diop (1978), numerous non-European societies of very ancient origins, such as those in Africa, are mainly matrilinear, and the female gender in those societies holds a high status. In many instances, females that belong to those social structures share equally the power and the rights with the male counterparts. Various matrilinear and matrifocal social constructs are found in the Americas, among the Native American cultural systems. Since the women of such cultures are respected for their achievements, their artistic productions are numerous and viewed by their societies as equally important as those of the male artists.

One of the many Native American cultures that can be cited for the purpose of this study is the Apachean tribal complex of the American Southwest. According to Dutton (1975), the ancestors of the Apacheans are usually designated as Paleo-Indians. These matriarchal tribes dwelt in the Southwest perhaps since 25,000 B.C.E. until about 6,000 B.C.E. Subsequently, the Paleo-Indians gave birth to the Desert Culture, and the Southwestern Indians are considered to be the descendants of a variation of that culture. The term "Apachean" defines the linguistic bond between the Southwestern tribes. Typically, the current 
Apachean societal organization, according to studies conducted by Kluckhohn and Leighton (1979), White (1979), Eggan (1983), and others is matrilocal and matrilinear. The clans may be strongly matrilinear, such as those of the Navaho, the Hopi, and the Western Apache tribes. The Apachean societies are Goddess or Mother God worshippers, and it is common to have female shamans as representatives of the spiritual life. In the Kiowa-Apache tribes, the women are believed to be the recipients of the supernatural powers. Their political leadership office is not hereditary, and the leader has only influence, but no absolute power; these societies present a picture of a very democratic, non-hierarchical construct.

The League of the Iroquois also consists of a matriarchal social structure. The women of the tribes never lose their clan identity, and their children inherit their clan lines (Morgan, 1975).

American Indian nations, including the Southwestern group, had a division of labor according to gender. This was also true in the area of artistic production and largely is still true today. Women created the pottery, the baskets, and the weaving; sometimes the building of the dwelling was relegated to the woman, partially or completely. The jewelry making was the work of the male, according to the tradition; however, it is currently a collaborative effort between the spouses and/or their 
children and relatives. Therefore, a very important and large portion of artistic production of the American Indian population was in the hands of the female gender. Many of these women artists have obtained worldwide recognition beyond the high respect of the Indian nations. Their work is avidly collected by numerous museums, and some have found their way into the token minority of female artists that are included in the college and university textbooks (Gilbert, $1992) \cdot$

In the realm of the matriarchal, Goddess worshipping system of human cultures, women artists have made many major and significant contributions to the cultural heritage (Gimbutas, 1989; Walker, 1985), yet even the knowledge of these facts is only recently reaching the imprisoned female psyche of today. Even so, it has become very obvious that the study of this past already has changed the level of creativity and artistic output of the women artists of the twentieth century. Inspired by the Prehistoric matriarchal heritage, numerous women artists originated or made major contributions to various new movements of this century, such as conceptual art, ritual art, earthworks, performance art and pattern art, among others (Lippard, 1983; Orenstein, $1990)$.

Lippard (1983) recognized the fact that of all the areas of research, thoroughly explored and adjusted to the patriarchal model by the male dominated historical 
perspective, Prehistory, although "colonized but not yet conquered by patriarchal scholarship" (p. 41), is the one area that offers strong models for women artists. At the same time, while inspired by prehistoric symbols, myths, and rituals, female artists attempt to reinsert themselves into the history of humanity as a whole. History survey books on women artists, authored by a handful of women art historians, such as Tufts (1973), Harris and Nochlin (1976), Fine (1978), and Peterson and Wilson (1978), did not appear on the art scene until the seventies. Earlier in the twentieth century, even token inclusion of women artists into art history books was eliminated (even though the initial art historical research by vasari and other early art historians of the patriarchal system included a few women in their surveys). Not one single woman artist was included in the art history texts of the school or college system of America, such as Janson (1971), Gombrich (1972), or Gardner (1976), throughout the first seven decades of this century.

Although historical research on women in art continues, most great women artists are still relegated to survey texts on women in art. These texts are used in higher education in women's studies programs, or as supplementary texts for survey courses in art history, together with the required texts that mention only a handful of women artists, if any. One excellent example of such text is the popular History of 
Art by Janson (1991). Generally accepted as the survey text at most universities, the new revised edition contains 2,300 male artists and only 19 female artists. Even surveys of twentieth century art contain a handful of women artists, in spite of the fact that they represent about half of the total number of contemporary artists of historical quality. Without the knowledge of their own history, and deprived of any role models, women artists continued to exist within the patriarchal establishment. Although it is hard to glean the correct figures, today approximately $50 \%$ of all artists are women. According to the Bureau of the Census (Dickinson, 1990), by 1980, professional women artists comprised $37.9 \%$ of the art labor force. The Bureau of Labor Statistics (Dickinson, 1990) indicated that by 1989 women artists went over the $50 \%$ mark, at $50.7 \%$. Therefore, the number of professional women artists in this country is at least between 40 and $50 \%$. Dickinson (1990) indicated that there were more female than male students admitted into the arts programs, according to the figures she obtained from the United States Department of Education. The numbers of students of female gender was higher in the Bachelor's of Fine Arts and the Master's of Fine Arts studio programs, at $56 \%$ and $60 \%$, respectively. The doctorates in art history, according to the College Art Association (Dickinson, 1990) reports, were about the same for both sexes. These figures reflect studies done during the 1988-89 period. While about 
the same number of graduate students of both sexes apply for faculty positions at the colleges and universities, those who actually are hired and later acquire tenure and promotion are mostly males. The figures obtained by Dickinson (1990) from the American Association of University Professors showed that as of 1978, full professors on the art faculties of the nation were $92 \%$ male and $8 \%$ female; and as their rank decreased, the number of female faculty increased, as follows: tenured faculty was $85 \%$ male and $16 \%$ female; full time faculty was $75 \%$ male and $25 \%$ female. By 1983, full time positions at institutions of higher learning that were occupied by male faculty were approximately 55\%, while female faculty was represented by approximately $42 \%$. Looking at these figures, Dickinson's (1990) report concluded that although $50 \%$ or more qualified women were available to fill these faculty positions, only $20 \%$ to $42 \%$ were hired, and the majority of these women remained in the lower faculty ranks. Statistics compiled by Chapman-Grant (1978) for Women's Caucus for Art in 1972-73 showed similar results. This phenomena was summarized by Harris (White \& White, 1973) as "the higher, the fewer." This statement indicated that women usually concentrated on the lower levels of the higher education system. The highest percentage of female faculty was usually found at the colleges offering the Associate of Arts (A.A.) degrees and the lowest was at those institutions that offered doctoral 
studies. White and White (1973), in the Women's Caucus for Art survey, suggested that the results of their study point to "the possibility of various kinds of discrimination related to hiring, promotion, and tenure" (p. 1), and that further investigation into this issue was necessary in order to provide more concrete answers.

Olin and Brawer (1988) postulated that it was very important to know how many women artists had solo exhibitions in the major galleries of major cities of America as well as the representation of women in the two major national group exhibitions: the whitney Biennial and the Corcoran Biennial. Their research indicated that due to the women's movement of the 1970s, the representation of women at the major city galleries seemed to peak between 1978 and 1983 to sometimes as high as 30 to $40 \%$ ratio of women to men, and then slid down to a range of 19 to $25 \%$ by 1985. The Corcoran Gallery in Washington, DC peaked at $40 \%$ in 1981, only to drop to $12 \%$ in 1985 . The percentage of women artists in the Whitney Biennial peaked in 1979 at $32 \%$, only to drop to $20 \%$ in 1981, while the 1985 figure stood at 29\%. Since exhibiting in the commercial New York City galleries constituted a very important step in any artist's career, olin and Brawer (1988) obtained survey figures showing more gender inequity in representation ratio of women to men in those commercial galleries. Between 1970 and 1985, the highest percentage of women artists having 
solo exhibitions in New York City galleries peaked at $24 \%$ in 1978, then gradually dropped to $16 \%$ in 1985 . The composite chart by the authors of several major cities indicated a peak figure of $26 \%$ in 1983 , and a more modest figure of $19 \%$ by 1985. Olin and Brawer (1988) noticed that from 1970 to 1985, 248 women artists of twentieth-century art movements were given a total of 321 solo exhibitions at the major museums nationwide. These were all established artists of international reputation. The 1985 figures, compiled by the authors, of solo exhibitions by women artists at the galleries across the nation ranged between 16 and $25 \%$. Even with the general drop in the statistical figures regarding women artists in the 1980s, this constituted an improvement as compared to the existing records of figures prior to the 1970s.

The figures that are available from various sources, including the survey by Dickinson (1990), demonstrated that the coverage by the elite art press was not balanced according to the gender ratio representation. The ratio of male to female artists covered by Los Angeles Times (198286) was $76 \%$ to $24 \%$. In 1986, Artforum coverage of women artists amounted to $16 \%$; Art News' $^{\prime}$ figure was $22 \%$, and $\underline{\text { Art }}$ in America reviewed women artists' works $25 \%$ of the time, while male artists received $75 \%$ of the magazine space (Dickinson, 1990). 
The surveys showed (Dickinson, 1990) that the J.S. Guggenheim Foundation awarded considerably fewer grants to women artists; the figures between the years 1970 to 1987 varied between the low figure of 7\% in 1972 and 1974 to the high figure of $36 \%$ in 1982. During the period of 1970 to 1988, the National Endowment for the Arts (NEA) figures obtained by Dickinson (1990) on the fellowships awarded to women artists by this government agency showed a range from $0 \%$ in 1972 , to a high of $40 \%$ in 1987 . It was also evident that women artists were awarded more lower level awards and fewer higher level fellowships. According to olin and Brawer (1988), in many cases, higher level awards for women were at $0 \%$ during the last decade, with most women receiving the lowest $(\$ 5,000)$ award; the next award, at $\$ 10,000$, had the highest figure for women in 1985 (36\%). A disparity in representation of women and men artists was obvious; most money was distributed to the male artists for their artistic development, while women artists were frequently left without governmental support.

\section{Educational System and Gender Attitudes}

Since the feminist movement of the 1970s, it may be presumed that sexist attitudes on all levels of education have been greatly diminished, and that both boys and girls in American schools, and men and women in American colleges and universities receive similar treatment, similar opportunities, and similar education. However, sexist 
attitudes are still very much in force at schools and college campuses; the boys and the men receive preferential treatment, have more complete participation in most fields of education, and have a privileged present and probably privileged future status in the area of sports. Above all, world history still belongs almost entirely to males. In almost all disciplines, recorded history as it presently appears in both school and college texts, is about male achievements and about male value systems. In those textbooks, the sociocultural environment is normally presented from the male point of view, the pictorial imagery is highly biased toward the male sex, and many textbooks still continue to use sexist language and sexist stereotyping.

The American Association of University Women (AAUW) Report, How Schools Shortchange Girls (1992), developed by the Wellesley College Center for Research on Women, confirmed the above statements. According to this report, our society perpetuated the cycle of poverty, by guiding girls away from the coursework that was necessary to give them skills, as women, to fully participate in the more lucrative professions that promote economic well-being. In schools, girls that absorbed male-oriented curricula received negative messages that lowered their self-esteem. This was accomplished through curricular omission and bias. The subtle message was that people like themselves were not 
important and not worth studying about. This report also revealed data of the power differentials and gender politics that took place within the school system, and the fact that these topics were a part of evaded curriculum. The report suggested the need for educational reform that would include "strong policies against sexual harassment" (p. 88), strengthening of the reinforcement of Title IX, the inclusion of women into the curricular models, dealing with the issues of sexual politics and the issues of power, the understanding of the importance of inclusion of girls into the disciplines of science and mathematics, and testing techniques that "accurately reflect the abilities of both girls and boys" (p. 87).

\section{$\underline{\text { Sexism in Textbooks }}$}

Sexism in textbooks, already discussed earlier in relation to the art history curricula in higher education, begins at the elementary school level. Numerous studies have found gender stereotyping to take place in school readers, and a typical girl character that emerged from those readers was a very passive, uninteresting individual, with a very limited range of interests.

The elementary school texts serve the school children as their main source of initiation into the social structure of the time, and as an indicator of what is expected of them within this particular culture. Bartl (1975) concluded that these readers clearly conveyed to the school children what 
this society expected from them, and that these young people will behave according to these societal expectations in their private and public lives. Bartl (1975) speculated that these societal expectations as conveyed through the material in the readers, may not at all match the natural predispositions of the child's personality, and may be very detrimental to the personal development of the young individual, as well as to this individual child's present and future happiness. There were two different messages in the readers for the students, and the one for the boys was the most desirable. Statistical analysis of Bartl's (1975) study showed that out of 134 New Jersey school books examined, the ratios of genders were quite different, as follows: adult male characters to adult female, $3: 1$; boy as main character to girl as main character, 5:2; male biographical stories to female biographical stories, $6: 1$; male animals to female animals, $2: 1$; and fantasy or folk story about a male to same type story about a female, $4: 1$. From these stories, at a very early age, the female child learned her secondary role in the society. The content analysis of this study also showed a great deal of imbalance. For instance, the "active mastery teams," defined by the author (Bartl, 1975) as such because of the concepts of bravery, adventureness, creativity, achievement and self-respect involved, had predominantly male characters, from young to old age. The ratio of male to 
female characters in these stories was $4: 1$. In the stories of what the author defined as "second sex themes," the female characters involved displayed totally different characteristics. The salient traits were passivity, dependency, fearfulness, and incompetence. These female characters emerged in supporting roles, conveying negative messages for the little girls, and, on a more subliminal level, a message of self-effacement, and the stereotypical role of domesticity. Another study (Stockard, 1980) found that in elementary texts for grades $\mathrm{K}$ to 3 , female children and adults were included much less frequently than the male characters, and that the adult females were often pictured in the house, while the males were represented in a business environment, or outdoors, or at school. This study observed the fact that while female characters often experienced the benefits of a positive conclusion of a situation, the male characters often experienced positive outcomes as a consequence of their own actions.

Math textbooks, examined by the Committee to Eliminate Sex Discrimination in the Public Schools (1971), showed that when arranged in groups, people were usually limited to one sex; these groups became rigid and stereotyped in terms of the professional occupations of the adults, and boys were represented as active, while girls were represented as passive. In those texts, the females seemed to have two interests: sewing and cooking. It was also noticed by the 
Committee that the higher the level of the math text, the more male-oriented it became. The Committee also noted that in science textbooks women's accomplishments were usually ignored, and history books included an insignificant number of women, while the textbooks on government did not quote, discuss, or include women's case histories, and illustrated an insignificant number of women. The message from these texts was that women did not belong in the history, science, or government of America. A study, titled Gender Bias in Human Anatomy Textbook Illustrations by Giacomini, RozeeKoker, and Pepitone-Arreola-Rockwell (1986), proved that college texts also discriminated against female students. In spite of the efforts during the decade since the implementation of Title IX in 1972, the authors wrote that "men continue to be treated as the primary benefactor of medical services" (p. 413). The authors examined the representation of female and male illustrations in the introductory anatomy texts. The textbooks selected were the required texts, and, therefore, most in demand at the college campuses. The publication dates ranged between 1973 and 1983. Only illustrations were researched. The researchers concluded from their resulting statistics that, "in standard human anatomy illustrations, males are practically the only subjects" (p. 417). This attitude, the authors concluded, was the direct result of the past development of medical sciences, when, traditionally, the 
female bodies were considered less valuable or worthy as patients to the physicians. They also saw this preference for the male figure as typical of a society that saw male as the norm, and female as the other, or second class. Female body illustrations only comprised $11 \%$ of the total of anatomical illustrations, giving the false impression that females were uncommon and/or not worth the attention that males received as patients. Most of the female bodies were found in the reproductive chapters of the texts, giving the impression that the most important function for the female body was reproductive, and with it, the most important role for a woman was that of a wife and mother. In this manner, the medical schools cooperated in perpetuating the traditional roles that were assigned within the patriarchal system to women.

\section{Perception of Sex Roles by} College Students

According to Bayer (1975), in the seventies, during the height of the feminist movement, college students had become "more liberal on virtually all political, economic, and social issues, including the role of women in modern society" (p. 391). Endorsement of traditional roles for women had steadily declined among the students on college campuses of the seventies. One interesting and comprehensive source of information on college freshmen who entered higher education for the first time, is the 
extensive survey, conducted by the American Council on Education (ACE) in 1972. This survey offered a rather comprehensive picture of the extent of sexist attitudes within the student population of the liberal and feminist decade of the seventies, and also a look at the demographics of these students. Data was collected by the ACE from 188,900 students who entered 323 higher level institutions across the country. From this total sample, a subsample of all students with a strong position toward the support of the traditional female role was selected. The subsample included approximately 23,700 students. The subsample also consisted of approximately $16 \%$ men and $8 \%$ women of the total of the original sample, or approximately $24 \%$ of the total of the original sample. The large amount of resulting data on these sexist students was analyzed, and the results, as briefly summarized here, were rather predictable. The demographic analysis showed that the students were mainly from Christian fundamentalist sects, were from the lower economic strata, and grew up in a small town or on a farm. The family incomes of these students were below national income average. The sexist students most likely graduated from a public school of a small size. These students were less likely to be highly successful in high school and more likely to have low grade point averages. Typically, sexist students had lower degree aspirations than the rest of the freshman students. While less than one-half of all freshman 
students aspired to a Bachelor's degree or less, $54 \%$ of sexist students displayed the same aspirations. The sexist students' future expectations also included emphasis on a marriage and family in the near future, and more desire to acquire wealth. Predictably, these students were more politically conservative. Their most frequently chosen professions were business, health professions, and education. These students were less likely to support equal opportunity for women.

A study on sex role identification was conducted on 109 undergraduate female and male students, who were assessed by the Bem Sex Role Inventory (BSRI) by Aronoff and McCormick (1990). The students were expected to produce drawings of either male or female human figures. It was observed that males and masculine persons tended to draw a male figure first, that females and feminine persons produced a female figure first, and that female subjects produced better quality female figure drawings. It was also determined that androgynous individuals tended to be as likely to draw a female or a male first. The study concluded that "these sex sequence results strongly support Machover's (1949) original hypothesis that facets of the human personality are in some way depicted in human figure drawings" (Aronoff \& McCormick, 1990, p. 465). The authors determined that the higher quality of female figure drawings by women in the study was attributable only to the subjects' concern with the 
appearance, reflecting their socialized beliefs in the female worth as associated with her beauty.

An examination of the relative importance of sex type and prestige preferences as part of the process in selecting a career has focused on a theory by Gottfredson (1981). She proposed that the process of examination of career included the prestige, the sex type (femininity or masculinity of the profession or occupation), and the field of work (such as science, arts, business, education, etc.). Gottfredson postulated that the individual chose his or her occupation within the acceptable range of prestige and sex type, and was likely to sacrifice prestige rather than sex type preference, when a compromise was necessary. A total of 151 female and 95 male undergraduate students participated in the study. The outcome of this study did not support Gottfredson's principles of compromise (1981). Generally, it was found that prestige was the preferred factor in making a career choice. An exception was found with the male participants, who, when forced to choose between higher prestige feminine occupation, and lower prestige masculine one, preferred the latter. It was also noted that both sexes seemed to have greater facility in sacrificing sex type for prestige, when the career in question was neutral in sex type. The prestige choice was most likely to be made by both men and women, when a choice was made between a low prestige occupation and a medium or high prestige 
occupation. According to this study, prestige was the most salient factor in the choice of a profession; the women participating in the study were particularly willing to consider nontraditional occupational options that afforded them more prestige.

Two studies on the sex role and social/personal effectiveness were conducted on male college students only. one study examined the male sex role orientation in the context of social/sexual relationships (Bem, 1985). One hundred and thirty-three male undergraduate students from two major universities were given the Bem Sex-Role Inventory (BSRI) and the Male Social-Sexual Effectiveness Scale (MSSES) tests. A one-way analysis of variance indicated that androgynous males had the highest scores on MSSES and that undifferentiated males had the lowest scores; masculine, sex-typed males had scores that fell in between the other two groups. These correlations suggest that a blending of the instrumental and expressive social competencies appear to produce a socially well-adjusted and socially effective individual. The second study was a replication of previous studies that investigated sex role orientation and personal adjustment (Harris \& Schwab, 1990). The study was performed on 74 male college juniors enrolled in secondary level teaching courses. The above mentioned BSRI and the California Psychological Inventory (CPI) were the instruments administered to the students. The results 
of the testing indicated that the males who rated themselves high on masculine (instrumental) attributes showed the highest CPI profiles, followed by the males who rated themselves high on both masculine (instrumental) and feminine (expressive), or androgynous males. The findings of this study suggested that both males and females that rated themselves high on the masculine traits seemed to display higher levels of social and personal adjustments (Harris \& Schwab, 1990). The testing method of this study may have been biased, since the qualities that were designated as masculine on the testing materials and by the authors usually were of active and positive nature, while those assigned by the testers and authors as feminine carried passive and sometimes negative connotations. The researcher believes that more equitable definition of terms as instrumental instead of masculine, and expressive instead of feminine would have eliminated some of the sexism from the testing procedure itself.

In 1989, Smith, Ulch, Cameron, Cumberland, Musgrave, and Tremblay investigated the influence of the sex of the stimulus person in their study of gender-related effects in the perception of anger. This study involved 166 female and 100 male university student volunteers from Ontario, Canada. The students were administered a modified version of the Extended Personal Attributes Questionnaire (EPAQ), a demographic questionnaire and a questionnaire designed by 
the researchers. The analysis of data yielded significant differences between the genders. Male students rated the female subjects' expression of anger as more appropriate and more well balanced, and saw female subjects engaging in angry behavior more frequently. These results suggested that males were more accepting of female anger, or that they were more aware of the consequences of expression of anger in women. Another gender difference appeared in the ratings of types of anger, such as physical or violent, or nonphysical or nonaggressive. Females seemed to be aware of the differences in the types of anger, while males were not. Female students rated the aggressive anger as less balanced and less appropriate, which may suggest that women may perceive a narrower range of anger behaviors as appropriate. Smith et al. (1989) point out that the aggressive vignettes presented interpersonal conflict, which presented a conflict with the female stereotype.

Several studies about differences in attitudes of women and men have been conducted. In a study of Australian students' attitudes to nuclear weapons by Peterson, Lawrence, and Dawes (1990), 46 male and 62 female freshmen university students were administered the Nuclear Attitudes Questionnaire (NARQ) and the Law and order Scale (L/O). The resulting data showed that women were significantly more opposed to the development, deployment and maintenance of 
nuclear arms than men. The women also placed themselves closer to the extreme on the scale of opposition than men.

\section{Sexist Language and Discourse in Higher Education}

All human knowledge, which includes art historical constructs, sexual politics, and educational systems, is interpreted through the use of language and the linguistic discourse. Therefore, sexist/stereotypical linguistic structure may be considered as the most powerful weapon of those who desire to maintain and perpetuate sexism on college campuses and, by extension, within our society. It may be argued that linguistic systems are given meaning through their use in actual discourse (McConnell-Ginet, 1984). According to McConnell-Ginet, gender may be seen as a "complex system of cognitive, symbolic, behavioral, political, and social phenomena mediated by sorting of people according to their sex" (p. 125). It works simultaneously with other factors, such as roles, personal attitudes and power relations.

Stanley (1977) pointed out that the cultural values that are built into our language determine our definition of sex roles; therefore, the dominance of male gender in a patriarchal culture prompted the use of males as the standard for human behaviors, and the behaviors of women are viewed as only a comparative or a contrasting element. According to Stanley (1977), the males have appropriated 
most of the linguistic construct for their own use. Stanley (1977) also observed that in the English language, gender marking consists of two unequal parts, female and male. The latter is immensely larger, and embodies most socially prestigious and financially rewarding positions, or positive semantic space. Within the smaller, female portion of this semantic space, many terms have negative connotations. Since the English language does not have a true generic person, Stanley (1977) suggested that at this time, the gender marking should be explicit, such as "chairwoman/chairman." Stanley contended that the opponents of the removal of sexist terminology from the English language intend to obscure the real issue, which is the issue of political power. She proceeded to state: "Our language is sexist because our society is sexist, and until there is a significant reversal of the prevalent attitudes toward women, we can not hope to accomplish much" (p. 74). Gladwin (1985) argued that "language has one of the most important roles in legitimizing this system of male hegemony because the normal language usage seems so natural to native speakers, just 'common sense'" (p. 14). Both the history and the politics of sex roles are embedded in everyday language. Sexual politics are deeply entrenched into the linguistic structure, and, therefore, are difficult to alter consciously. This deeply ingrained linguistic construct entraps even those who consciously resist it and 
are motivated to change its discriminatory powers. While the terminology that indicates female gender is marked, the male gender terms function as unmarked and, at the same time, they indicate the absence of the marked, or the feminine. The most unmarked people in our American society are white males, which means that these are the people with the most access to power, wealth and status. Thus, the language constitutes one of the most important tools to maintain and legitimize male supremacy

Gladwin (1985) described four distinct linguistic "effects" that are usually advantageous to the unmarked semantic space: unmarked terminology encompasses the whole linguistic domain, or "the entire set of things being evaluated" (p. 7); the use of a marked term is more unusual, therefore it is more noticeable, which is often disadvantageous to the subject involved; and the use of an unmarked term usually implies that the marked term is not present or represented. The linguistic hierarchies that contain unmarked terms can operate on several levels of comprehension and communication, while marked hierarchies often cause linguistic ambiguity that can only be resolved by "extra-linguistic knowledge" (p. 10).

Recent findings seem to indicate that in the present culture, men tend to dominate the discourse and are likely to interrupt women, initiate conversations and introduce new topics (Zimmerman, 1975; West, 1979; McConnell-Ginet, 1984). 
When a discourse among men and women takes place, women mostly participate as supporters or clarifiers, rather than as leaders. McConnell-Ginet (1984) explains:

When a woman, say, Ms. A., does introduce a topic or make some suggestions in a faculty meeting, Eakins and Eakins found that others tend to appropriate the idea. $\mathrm{Mr}$. B. for example, may present it as if novel and others identify it later as Mr. B.'s proposal. They may make this identification even if Mr. B. himself actually credits Ms. A. and just supports her. In sum, even where a woman does get her own point made, someone else may claim it as his own. (p. 127)

Gender, therefore, determines how human beings think that they could contribute to a discourse, how they actually contribute, and how they themselves and others perceive their contribution (McConnell-Ginet, 1984).

Due to the feminist movement and its demands for nonsexist written language, the American Psychological Association (APA) issued specific guidelines in 1974. The guidelines suggested to journal authors that they should, among other things, avoid the generic use of male nouns when these refer to both sexes. The second change sheet was published by the APA the following year, and it offered some general suggestions and principles for the authors to follow in order to avoid the use of sexist terminology. Yet, many linguists continued to oppose the very idea of any changes in traditional, male-oriented use of written or spoken language. Cameron (1985) argued that grammatical categories used in linguistic description were not neutral or devoid of ideological significance. She observed that there was a 
complex interaction between the linguistic, or what human beings say, and the metalinguistic, or how human beings theorize what they say. Cameron (1985) indicated that language is affected by political structures and their cultural norms. The use of masculine gender as a norm is consistent with the patriarchal structure of society. Black and Coward (1981) contend that patriarchy equates women with sexuality, thus men become the norm, the sexless sex, when sexuality is not an issue.

Both males and females who hold traditional sex-role beliefs, tend to devalue females that operate in traditionally male occupational roles, which applies to a wide range of professions and occupations. According to Broverman, Broverman, Clarkson, Rosenkrantz, and Vogel (1971), the very existence of gender stereotypes is supported by this social structure, so that females can be devalued, relative to males. For instance, males were perceived as superior to females in an art contest where their artistic talents were not legitimized by a jury action (Pheterson, Kiesler, and Goldberg, 1971). Routinely, the accomplishments of a female are viewed as being of lesser magnitude, talent, or importance than similar accomplishments of a male (Dayhoff, 1983). The factors in this perception are several, including the locus of control attributed to each gender; the male's success is equated with his inner locus of control, such as his successful 
performance, while the female's success is equated with outer locus of control, such as good luck (Deaux \& Emswiller, 1974). Perhaps one of the most salient factors that help perpetuate sexual stereotypes is linguistic sexism. The belief that sexist language significantly affects the perception of candidates for office was explored in a study by Dayhoff (1983). The subjects of this study were 329 female and 300 male students from a large university. The subjects were supplied with three stories, and independent variables that were manipulated included the sex of the candidate for office, the degree of sexist language used in the description of the candidate, and the gender appropriateness of the particular elective office. The results of the analysis of variance suggested, as predicted, that sexist language had an effect on the evaluation of the female candidates who ran for traditionally neutral or masculine offices, and suggested that female candidates for offices that were sex neutral or masculine would be devalued, unless they were running for a feminine office. Dayhoff (1983) concluded that sexist language has the power to perpetuate and reinforce sexual stereotypes.

Several studies have been conducted to investigate the fact that there are sex differences in the use of language. However, there has been very little concern on the part of the sociolinguists with the cause of these differences. 
Cameron and Coates (1985) questioned the reasons why these linguistic differences exist. While women's speech is more conservative and status conscious, it is also very sensitive to change. Women may also try to hypercorrect, in order to try to gain status through their speech patterns, yet, the society sets higher standards for women's speech behavior, while offering little prestige in return. If women gain very little prestige through their speech practices, then the men, who use more non-standard and stigmatized forms, acquire covert prestige through their use of speech patterns (Cameron \& Coates, 1985). The authors criticized current sociolinguistic methodology which tends to ignore the organization and the values of women's subculture. They posited that a redefinition of the so-called speech community is necessary to include women. It $s$ also necessary to give up the framework that believes that only male speech norms are prototypical (Cameron \& Coates, 1985). The study that particularly reflects the interests of this researcher and which was partially replicated, was the Lipton and Hershaft (1984) experiment to investigate the effects of sexist labeling on the perception of college students who were asked to evaluate an artist's work on a variety of cognitive and affective measures. This artist was given sex neutral identification. The participating students were 60 females and 60 males, half of whom were enrolled at a large state university and the other half at a 
community college. The students were given booklets with information on the artist, who half the time was identified as a male and the other half as a female. The booklets were similar to those used by Pheterson et al. (1971). The linguistic labels of either "girl," "woman," or "person" for a female artist and "man," "guy," or "person" for a male artist were added to test the students on the effects of sexist language. The subjects were randomly selected for the six experimental situations. A three-way analysis of variance and Tuckey statistical testing was applied, and the results, as in the previous similar studies, exhibited prejudice against women, this prejudice was equally evident in both men and women. The study also suggested that such prejudice could be remedied by the use of non-sexist language. One unexpected finding of this study was the discovery that when the female artist was labeled either a "girl" or a "woman," her ratings were equally low; however, when she was labeled a "person," her ratings were among the highest of the study, close to the ratings of the male artist. The reverse would occur to the male artist. His ratings were just as high whether he was labeled a "man" or a "guy," only when he was labeled a "person," his ratings were among the lowest, within the range of the lower ratings attributed to the female artist. The authors explain this phenomenon by suggesting that in our society, it has become acceptable to label a successful female a "person," while a 
successful male would still be called a "man" or a "guy." The term "person," when applied to a male, has become an emasculating term. Therefore, a male labeled as "person" would acquire the same connotations as a non-achieving female.

Some possible limitations of this study included the sample itself. A larger sample, with cultural, ethnic, or regional variations, as well as social environment, needs to be explored. The institutional and educational sexism also needs to be explained. The implications of sexist labeling and sexist language have extremely important consequences in higher education and the society in general, since both usually work on unconscious and covert levels.

\section{Summary}

This review of literature examined the historical background, establishing the present gender biased art historical research, the gender biased educational system and the sexist language. All were generated by the patriarchal structure of our society, which had dominated this culture for over 2,000 years, and which still constitutes the mainstream of our post-modern society. The study by Lipton and Hershaft (1984), which examined the gender related attitudes of college students and their perception of visual artists, based on the artists' gender, was of particular importance as a source of inspiration and replication for the following study. 
CHAPTER III

Methodology

The purpose of this study was to investigate and determine whether community college and university students displayed sexist behaviors in affective and cognitive domains when perceiving works of art by female and male artists, and whether sexual labels, attached to the artists, determined the affective and cognitive perceptions of these students. In this chapter, the methodology of the study, the participants involved, the procedure selected, and the instruments utilized are described and explained.

\section{Research Method}

This study was based in part on a prior study by Lipton and Hershaft (1984) that also investigated the effects of sexist labeling by college students on a variety of cognitive and affective measures. In addition, the study investigated the sexual attitudes of the participants. The investigator utilized a survey method to test the hypotheses, as listed in Chapter I, at .05 level of significance.

\section{Population}

The population of this study included students enrolled in classes at Broward Community College, South Campus and 
students enrolled in classes at Florida International University, University Park Campus and North Miami Campus, during the spring and Summer semesters, 1992. The population sample was from a large urban community in south Florida. Most were residents of two densely populated counties, Dade and Broward. The students commuted to campuses from their residences, and most held part-time jobs. The two educational institutions, Broward Community and Florida International University, were both multicampus, large colleges with thousands of students on each of the campuses.

\section{Sample}

The sample population included students from art history, humanities, English, education, and anthropology classes. The classes were selected to participate in the study according to the willingness and the cooperation of the instructors. The humanities classes were selected because of the inclusion of art appreciation courses in the area, and because these and other courses, such as English, constitute the core of the required academic courses. It was assumed that because of the nature of these required general education courses, a fairly representative sample of the student population was represented in this study. Out of 10 instructors asked to participate in the study, 7 ( 4 females and 3 males) agreed to survey their 
students. The art history class was surveyed by the investigator.

The participants of this study were 370 students from Broward Community College, South Campus and Florida International University, University Park and North Miami Campuses. The students were enrolled in art appreciation, art history, anthropology, English, education, or humanities courses: 253 were from Broward Community College, South Campus, and 127 were from Florida International University Campuses. The study was conducted during the spring and Summer semesters of 1992. Class sizes varied from 20 students to 100 students per section, as follows: the art history course and four sections of English had 20 students each, the four sections of art appreciation courses had 35 students each, the anthropology course had 35 students, and the education course had 110 students. Absences or tardiness reduced the total figure for the participants to 370 students.

As described in Table 1, the population sample consisted of 253 females, 115 males and two students of unknown gender (no response was marked). The demographic cross-section of the students showed that $3 \%$ of the sample population were Native American, $12.2 \%$ were Black, $31.6 \%$ were Hispanic, $1.4 \%$ were Oriental, $48.4 \%$ were Caucasian, $5.7 \%$ of students were marked on the survey as other, and $.5 \%$ 
Table 1

Ethnicity of Students Participating in the study

Students

Frequency

Percent

Native American

Black

Hispanic

117

31.6

oriental

5

1.4

Caucasian

179

48.4

Other

21

5.7

No response marked

2

.5

Total

370

100.0

of students were of unknown origin (no response was marked). The participation was voluntary and anonymous.

The educational background of the population sample, as described in Table 2, demonstrated that $16 \%$ of the students completed less than one semester of study, $30.5 \%$ of the sample completed one year of study, $27.8 \%$ finished two years of study, and $11.9 \%$ completed three years of undergraduate study. The students that completed four years of study comprised $6.5 \%$ of the sample. The students that completed five years of college reached $2.2 \%$, while the students with 
Table 2

Years of College Completed of Students Participating in the $\underline{\text { study }}$

Years complete

Frequency

Percent

1 semester or less

18.1

1 year

113

30.5

2 years

103

27.8

3 years

44

11.9

4 years

24

6.5

5 years

9

2.4

More than 5 years

Left blank

Total

370

100.0

more than five years of college education comprised $2.4 \%$ of the sample population.

Table 3 shows that the majority of the students that participated in the study did not receive any degrees at that time; they comprised $73.2 \%$ of the population sample. However, $20 \%$ of the students received their A.A. degrees, $4.6 \%$ had a B.A. or a B.S. degree, $1.6 \%$ were graduate students and $.5 \%$ stated that they were not aware of their level of education. 
Table 3

Type of Degree of Students Participating in the study

Years complete

Frequency

Percent

No degree

271

73.2

A. A.

74

20.0

B.A. or B.S.

4.6

Graduate

6

1.6

Don't know

2

.5

Total

370

100.0

Table 4 demonstrates that the results of the demographic questionnaire indicated that $43.7 \%$ of the participants were between the ages of 18 and 21 . The total range of the age of the sample population was very wide; the oldest participant was over 70 years of age, and the three youngest students were 17 years old.

\section{Instruments}

The investigator provided the participating instructors in this study with an introductory letter (Appendix A) and several items that served as the "instruments." Included were five slides of artwork in a carousel (including appropriate projection equipment), along with a packet 
Table 4

Age of the Participating Students

Year born

Frequency

Percent

1920

1

3.0

1927

1

.3

1941

1

.3

1943

4

1.1

1946

2

.5

1947

5

1.4

1948

2

.5

1949

4

1.1

1950

4

1.1

1951

3

.8

1952

5

1.4

1953

1

.3

1954

3

.8

1955

3

.8

1956

2

.5

1957

4

1.1

1958

4

1.1

1959

4

1.1

1960

4

1.1

1961

7

1.9

(table continues) 


\begin{tabular}{|c|c|c|}
\hline 1962 & 8 & 2.2 \\
\hline 1963 & 8 & 2.2 \\
\hline 1964 & 11 & 3.0 \\
\hline 1965 & 2 & .5 \\
\hline 1966 & 9 & 2.4 \\
\hline 1967 & 17 & 4.5 \\
\hline 1968 & 15 & 4.1 \\
\hline 1969 & 20 & 5.4 \\
\hline 1970 & 29 & 7.8 \\
\hline 1971 & 57 & 15.4 \\
\hline 1972 & 6 & 16.8 \\
\hline 1973 & 56 & 15.1 \\
\hline 1974 & 6 & 1.6 \\
\hline 1975 & 3 & .8 \\
\hline Not known & 3 & .8 \\
\hline Total & 370 & 100.0 \\
\hline
\end{tabular}


containing an artist's biographical sketch (Appendix E). The artist had a sex neutral name. The six versions of the biographical sketch of the artist actually contained the experimental manipulations. The artist's sexual labels, embedded in the biographical sketch (Appendix E), were the manipulations. The labels were high status (woman), low status (girl), and neutral (person-she) for the assumed female artist; high status (man), low status (guy), and neutral (person-he) for the assumed male artist. A nine item Artist Evaluation Questionnaire (Appendix F) was designed to test the sexual labels. The questionnaire items measured perceptions related to the following items: the creativity of the artist, (b) the extent of the emotional reaction of the subject towards the artwork by this artist, (c) the technical ability of the artist to control the medium used in the artwork, (d) an estimate of the value (total price) of the five artworks, (e) the rating of the artist's intelligence, (f) the rating of the artist's talent, (g) the subjects' rating of the desire to display this work in their home, (h) the subjects' liking of the artist, and (i) the subjects' prediction concerning the artist's future career success. The testing instruments also included a 12 item demographic questionnaire (Appendix G) and the Bem Sex Role Inventory (BSRI) instrument, called the Attitude Questionnaire (Appendix $H$ ) to determine their sex role orientation. 
The Bem Sex Role Inventory (BSRI) was developed in 1974 by Bem in order to provide construct validation for the concept of androgyny. It was chosen for this study due to its ability to measure behavior patterns and personality characteristics as they relate to sex roles. Reliability of BSRI has been demonstrated between .70 and .86 using the coefficient alpha (Bem, 1974). Previous studies suggest that the femininity and masculinity scales are correlated with sex role related behaviors.

\section{Procedure}

In order to initiate data collection, permission was obtained from the Community College and the University involved. The schedule for the administration of the tests was planned to avoid the proximity of mid-term and final exams. This prevented the possibility of anxiety factors, associated with testing, from interfering with the reliability and the validity of this study. The testing took place during the spring and summer semesters of 1992.

Each participating class was provided with a carousel containing five slides, and equipped with a slide projector and a screen. The participating students were shown five slides of paintings by a woman artist of regional recognition, but whose work they probably have not previously seen. Informal pretesting demonstrated that this abstracted work did not elicit strong emotional response of either a negative or positive nature. Each subject was 
given a packet with a letter requesting participation, instructions (Appendix B), and a biographical sketch of an artist with an androgynous fictitious name and with imbedded experimental manipulations. The five slides were shown for approximately 30 seconds each. Immediately after, students read the biographical sketch of the artist. After students viewed the slides, the slide projector was turned off. The Artist Evaluation Questionnaire, using the seven-point Likert scale with the experimental manipulations also imbedded, was then completed by the participants. A Demographic Questionnaire (Appendix G) of 12 items and the Bem Sex Role Inventory questionnaire, titled the Attitude Questionnaire, were also completed by the participants. This last questionnaire had 60 items, 40 of which were to be used as a testing instrument.

Immediately after collecting all the completed questionnaires, the subjects were debriefed concerning the general purpose of this study. An average of 30 minutes was required for the subjects to complete the experiment.

The general attitude of the group was very positive; however, two individuals from the older age group (30-60) complained about the length of the Attitude Questionnaire.

A causal comparative design was used to analyze the results. This design was a $2 \times 2 \times 3 \times 3 \times 3$ factorial with the variables being the sex of the subject, sex of the artist, the condition of the artist's label, and the sex role 
personality (expressive, instrumental, or androgynous) of the subject. All the subjects were randomly assigned to one of the experimental conditions: a female artist with a high status label (woman), low status label (girl), or a gender neutral label (person); or a male artist with a high status label (man), low status label (guy), or a sex neutral label (person). A series of three-way Analysis of Variance (ANOVA) were administered to the resulting data to determine the means and the F-ratios.

\section{Assumptions}

For the purposes of this study, it was assumed that:

1. The students that participated in this study were representative of the general population of the two institutions involved.

2. The Bem Sex Role Inventory (BSRI) was a reliable and valid instrument for measuring sex role attitudes.

3. The subjects rated the questionnaires according to perceived sex role orientation, rather than on perceived social desirability.

\section{Limitations}

The researcher recognizes that the conditions, as described below, may have influenced the results of this study. Therefore, it is advisable to exercise caution before generalizing this study's finds. 
1. The population sample that was used for this study was limited to the available participating classes at Broward Community College, South Campus and Florida International University, University Park and Bay Vista Campuses. The classes were involved in the study because the faculty volunteered to participate (see Appendix A).

2. Cognitive and affective perceptions of artwork may vary, due to the particular mood or state of alertness of an individual subject, and may not be accurate indicators of reliability or validity of a study.

\section{Assurance}

The subjects of this study were advised of confidentiality of their responses and participation in a cover letter (Appendix C) for this study. The cover letter also informed the students that their participation was voluntary and anonymous. None of the data that would identify the student, such as name or student number, was requested.

\section{$\underline{\text { Summary }}$}

The purpose of this study was to investigate and determine whether community college and university students displayed sexist behaviors in affective and cognitive domains when perceiving works of art by female and male artists, and whether sexual labels, attached to the artists, determined the affective and cognitive perceptions of these 
students. To achieve this purpose, 370 community college and university female and male students participated. The procedure included the viewing of 5 slides, 6 versions of artist's biographical sketch, a 9 item Artist Evaluation Questionnaire, a demographic questionnaire, a Bem Sex Role Inventory (BSRI) questionnaire called the Attitude Questionnaire, and a letter of explanation (Appendix D). A handout with instructions was also given to the participating faculty (Appendix B).

A causal comparative design was used, with a series of three-way analyses of variance tests.

The study investigated the effects of sexist labeling on the perception of visual artists by community college and university students and determined their sex role orientation. 
CHAPTER IV

Analysis of Data and Results

The purpose of this study was to investigate and determine whether community college and university students displayed sexist behaviors in affective and cognitive domains when perceiving works of art by female and male artists, and whether sexual labels, attached to the artists, determined the affective and cognitive perceptions of these students. The statistical analysis that follows was designed to test, at the $p<.05$ level of significance, the hypotheses that were presented in Chapter I.

\section{Definition of Variables}

The Artist Evaluation Questionnaire (Appendix F) variables are defined as follows:

Creative: In your personal opinion, how creative is the artist?

Emotional: Is this artist's work emotionally appealing to you?

Technique: In your opinion, how competent is this artist in terms of the technique of painting?

Value: These five paintings were purchased by the Art in Public Places Program. Please give your best estimate of the price (value) of all five works? 
Intelligence: In your opinion, how does the artist impress you in terms of intelligence?

Gifted: How gifted (possessing natural artistic ability) does this artist seem to be, according to your perception?

Display: Would you be willing to display this artist's works at your own home?

Like: How much do you like this artist, judging from the work seen?

Success: In your opinion, what kind of future success is this artist capable of achieving?

\section{Analysis of Data}

In order to test Hypotheses 1 through 8 , the study participants were given the packets containing the six versions of the artist's biography, the demographic questionnaire and the attitude questionnaire. This allowed all of the possible combinations of groupings, necessary to test these hypotheses, to take place.

Hypothesis 1

There are no statistically significant differences in perceptions of a female or male artist's work by community college and university students.

The Analysis of Variance that was performed on the data collected from the community college and university students of both sexes revealed the following: one question 
(Success) out of nine items on the Artist Evaluation Questionnaire showed a statistically significant F-ratio when the mean responses were compared with the $p<.05$ level of significance, and one (Emotional) revealed a borderline significance. The results of each question are presented in Table 5 .

The Artist Evaluation Questionnaire demonstrated that, whether the difference was statistically significant, borderline significant, or not significant, the means for all nine items were higher for the assumed female artist, and lower for the assumed male artist. Question 2 (Is this artist's work emotionally appealing to you?) had a p-value of borderline significance of .0785, where the margin between female and male artist was in favor of the female artist. Question 9 (In your opinion, what kind of future success is this artist capable of achieving?) revealed that the assumed female artist received a statistically significant higher rating than the assumed male artist. Therefore, hypothesis 1 was rejected.

\section{Hypothesis 2}

There are no statistically significant differences in perception of a female or male artist's work between female and male community college and university students.

The Analysis of Variance was performed on the data collected from the community college and university students, testing the variance of the female sample 
Table 5

Responses of Female and Male Students to the Artist Evaluation Questionnaire Rating Gender of Artist

\begin{tabular}{|c|c|c|c|c|}
\hline \multirow{2}{*}{$\begin{array}{c}\text { Questionnaire } \\
\text { item }\end{array}$} & \multicolumn{2}{|c|}{ Mean } & \multirow[b]{2}{*}{$\mathrm{F}$} & \multirow{2}{*}{$\begin{array}{c}\text { Significance } \\
\text { of } F\end{array}$} \\
\hline & Female & Male & & \\
\hline 1. Creative & 4.5241 & 4.3333 & 1.8825 & .1709 \\
\hline 2. Emotional & 3.5397 & 3.2369 & 3.1121 & .0785 \\
\hline 3. Technique & 4.2963 & 4.1389 & 1.1407 & .2862 \\
\hline 4. Value & 2.3915 & 3.3073 & .2998 & .5844 \\
\hline 5. Intelligence & 4.6349 & 4.4494 & 1.8393 & .1759 \\
\hline 6. Gifted & 4.2751 & 4.1722 & .3949 & .5201 \\
\hline 7. Display & 2.5526 & 2.2961 & 2.0839 & .1497 \\
\hline 8. Like & 3.3737 & 3.0833 & 2.3635 & .1246 \\
\hline 9. Success & 4.3743 & 4.0335 & 5.1564 & $.0237 \star$ \\
\hline
\end{tabular}

*Significant at the .05 level 
population only, and then testing the variance of the male sample of the population. A comparison of the results showed no statistically significant F-ratio, when the mean responses were compared with the p-value <.05 level of significance for the female participants on all nine items of the Artist Evaluation Questionnaire. However, a comparison of the results for the male participant students showed four items out of nine on the Artist's Evaluation Questionnaire had a statistically significant F-ratio, when the mean responses were compared with the $p<.05$ level of significance, and one item revealed a borderline significance. The results of each question are described in Tables 6 and 7 .

The ratings of the female students of the assumed female and the assumed male artist demonstrate that the mean for the female artist was higher than the mean for the male artist, with the exception of question 8 (How much do you like this artist, judging from the work seen?). However, none of the nine means were statistically significantly higher than the means of the male artist.

The responses of the male students indicate that these participants rated the assumed female artist higher than the assumed male artist on all nine items. Question 2 (Is the artist's work emotionally appealing to you?), question 3 (In your opinion, how competent is this artist in terms of the technique of painting?), question 4 (These five paintings 
Table 6

Responses of Female Students to the Artist Evaluation Questionnaire Rating Gender of Artist

\begin{tabular}{|c|c|c|c|c|}
\hline \multirow{2}{*}{$\begin{array}{c}\text { Questionnaire } \\
\text { item }\end{array}$} & \multicolumn{2}{|c|}{ Mean } & \multirow[b]{2}{*}{$F$} & \multirow{2}{*}{$\begin{array}{l}\text { Significance } \\
\text { of } F\end{array}$} \\
\hline & Female & Male & & \\
\hline 1. Creative & 4.4120 & 4.3934 & .0460 & .6304 \\
\hline 2. Emotional & 3.4651 & 3.2500 & 1.0441 & .3079 \\
\hline 3. Technique & 4.1938 & 4.1694 & .0185 & .8918 \\
\hline 4. Value & 2.4652 & 2.4146 & .0714 & .7895 \\
\hline 5. Intelligence & 4.6047 & 4.5691 & .0530 & .8181 \\
\hline 6. Gifted & 4.2558 & 4.1774 & .1551 & .6940 \\
\hline 7. Display & 2.3566 & 2.2984 & .0729 & .7874 \\
\hline 8. Like & 3.1163 & 3.1290 & .0030 & .9561 \\
\hline 9. Success & 4.2656 & 4.1048 & .8724 & .3512 \\
\hline
\end{tabular}

*Significant at the .05 level 
Table 7

Responses of Male Students to the Artist Evaluation Questionnaire Rating Gender of Artist

Questionnaire item
Mean

Female Male

Significance

F of $F$

\begin{tabular}{lcccc} 
1. Creative & 4.7241 & 4.2549 & 3.8222 & $.0532 *$ \\
2. Emotional & 3.6959 & 3.2545 & 2.2651 & .1351 \\
3. Technique & 4.5424 & 4.1273 & 2.6569 & .1059 \\
4. Value & 2.2542 & 2.0909 & .3768 & .5406 \\
5. Intelligence & 4.7288 & 4.1818 & 3.9442 & $.0495 *$ \\
6. Gifted & 4.3559 & 4.2182 & .2301 & .6324 \\
7. Display & 3.0000 & 2.3148 & 4.8262 & $.0301 *$ \\
8. Like & 3.9333 & 3.0185 & 8.2615 & $.0048 *$ \\
9. Success & 4.6379 & 3.9259 & 5.8824 & $.0169 *$ \\
\hline
\end{tabular}

*Significant at the .05 level 
were purchased by the Art in Public Places Program. Please give your best estimate of the purchase price/value of all five works), and question 6 (How gifted/possessing natural artistic ability this artist seems to be, according to your perceptions?) did not have statistically significant differences, since the p-value was greater than .05 .

The ratings of the male participants of this study show that question 1 (In your personal opinion, how creative is this artist?) is extremely close to having a statistically significant difference of means, in favor of the assumed female artist, with the p-value of .0532. Therefore, it was concluded that this p-value was considered statistically significant for the purpose of this study.

Questions 5, 7, 8, and 9 of the Artist Evaluation Questionnaire, answered by the male respondents, all showed statistically significant F-ratios, as follows:

Question 5 (In your opinion, how does this artist impress you in terms of intelligence?) had the mean for the female artist of 4.7288 , and the mean for the male artist of $4.1818 ;$ the p-value at .0495 was statistically significant in favor of the female artist.

Question 7 (Would you be willing to display this artist's work at your own home?) rated by male subjects, revealed the mean for the female artist at 3.000, and the mean for the male artist at 2.1348 . This mean relationship 
showed a statistically significant F-ratio when the mean responses were compared with the p-value of $.0301(\mathrm{p}<.05)$.

The ratings of question 6 (How much do you like this artist, judging from the work seen?) by male students displayed the mean for the female artist of 3.9333 and the mean for the male artist of 3.0182 ; the F-ratio, with the pvalue of .0048 , was statistically significant.

The ratings by male students for Question 9 (In your opinion, what kind of future success is this artist capable of achieving?) showed the mean for the female artist of 4.6379, and the mean for the male artist of 3.9259 ; the Fratio, with the p-value <.05, of .0169 , was statistically significant.

On the basis of the above information, a significant difference between the responses of the female and the male gender of respondents can be observed. The male students rated the female artist significantly higher than the male artist, therefore, hypothesis 2 was rejected.

\section{Hypothesis 3}

There are no statistically significant differences in perception of a female artist's work when referred to as "woman," "girl," or "person," by female and male community and university students.

The Analysis of Variance was performed on the data collected from the community college and university students, testing the entire group of participants. A 
comparison of the results revealed that students of both genders gave the assumed female artist higher ratings when she was given the neutral sexual label of a "person." However, only question 8 (How do you like this artist, judging from the work seen?) produced a borderline statistically significant F-ratio ( $p$-value was .0749) in favor of the neutral label, "person" (see Table 8).

The analysis of the means of this study confirm that both genders gave the female artist, when referred to as a "person," the highest ratings. The analysis of the figures of this study shows that all the participants rated the female artist when referred to as a "girl," the second highest ratings. The analysis of this study demonstrates that all the students gave the female artist when referred to as a "woman," the lowest ratings. While the means show the above preference, only question 8 (like) obtained a borderline statistically significant F-ratio, with the pvalue of .0749 in favor of the neutral label of a person. Therefore, hypothesis 3 was not rejected.

\section{Hypothesis 4}

There are no statistically significant differences in perception of a female artist's work, when referred to as "woman," "girl," or "person," between female and male community college and university students.

The Analysis of Variance was performed on the data collected from the community college and university 


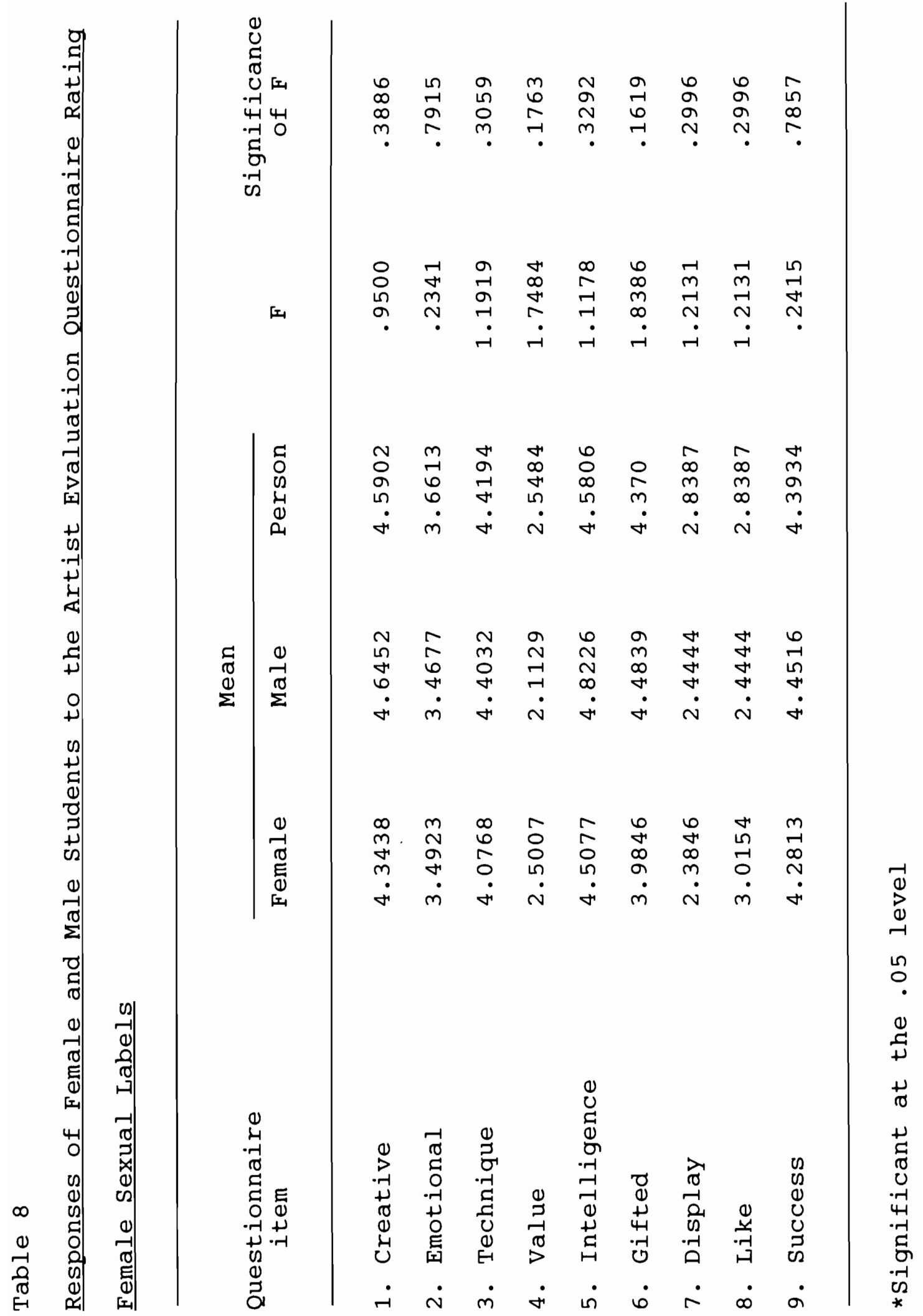


students, testing the variance of only the female sample population, and then testing only the male sample of the population. A comparison of the results showed a statistically significant F-ratio when the mean responses were compared with the p-value of $<.05$ level of significance for the female and the male group of participants.

The results indicate that the female participants who rated the assumed female artist's work preferred the neutral sexual label "person." However, only question 8 obtained a statistically significant p-value of .0268. The male participants of this study preferred the female artist's work when she was addressed as a girl, the low status sexual label. However, only question 5 (intelligence) obtained quasi statistical significant (p-value was .0589). The high status label, "Woman," was the male participants' second preference and had one borderline significant p-value which was .0750 (see Tables 9 and 10 ).

The ratings of the population sample of the Artist Evaluation Questionnaire of the assumed female artist's work indicated that there were statistically significant differences between the responses of the female and the responses of the male students of the population sample. The responses of the female students that rated the assumed female artist indicated that the female artist's work, when she was presented as a "person," received highest (questions 1 through 8), or second highest (question 9) 


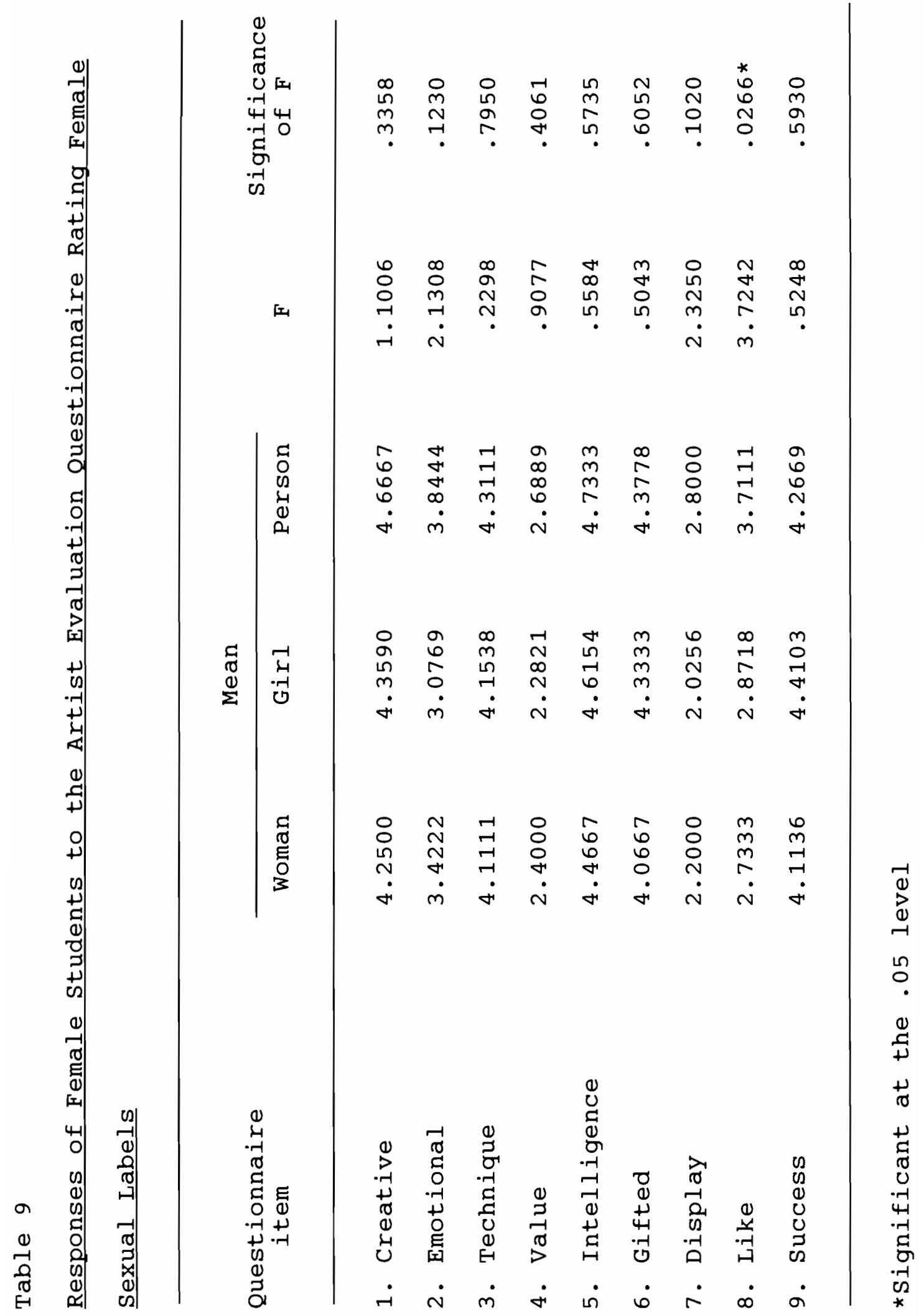




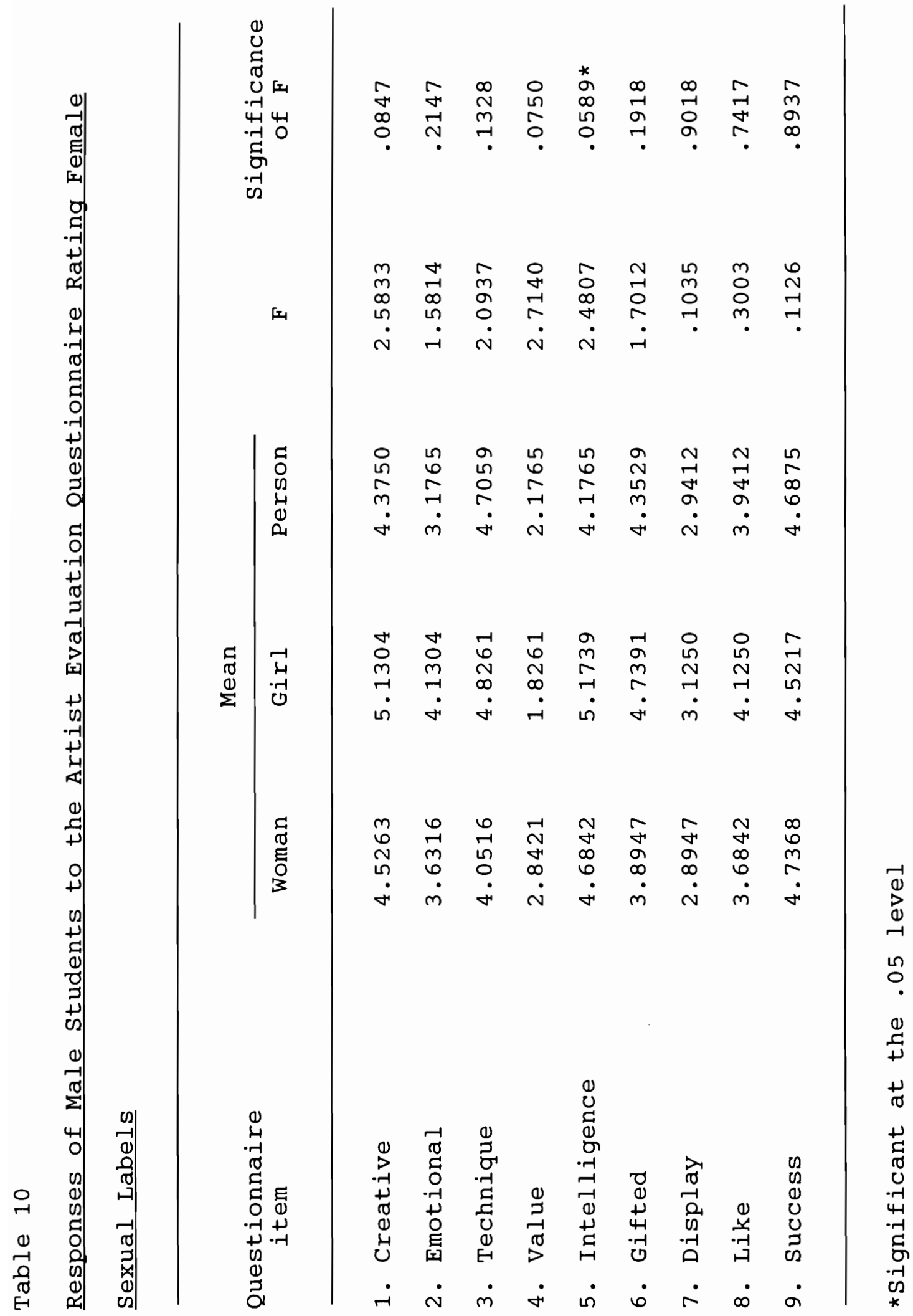


ratings. Only question 8 (How much do you like this artist?), displayed a statistically significant F-ratio. The responses of the female students that participated in the rating of the assumed female artist's work revealed that when she was referred to as "girl," she received second overall highest ratings; however, these were lower than those of the female artist when labeled as a "person" (question 8 received highest ratings, questions $1,3,5,6$, and 9 received second highest ratings, and questions 2, 4, and 7 received lowest ratings).

The participating female students' responses to the questionnaire indicated that the lowest overall rating was given to the assumed female artist's work when she was referred to as a "woman" (questions 2, 4, and 7 gave the artist her second highest ratings, and the questions 1,3 , $5,6,8$, and 9 gave the artist her lowest ratings).

While the preference among the female participants of this study for the neutral label of a "person" for a female artist was statistically significant, the slight preference for the label "girl" over the label "woman" was small and was not statistically significant.

The male participants of this study gave their highest rating to the assumed female artist's work when the artist was referred to as a "girl." This highest rating is statistically significant. The female artist, when addressed as a "girl," received top ratings from the male 
students on questions $1,2,3,5,6,7$, and 9; however, not all were statistically significant ratios. Question 1 (How creative is the artist?) revealed a borderline statistically significant F-ratio (p-value was .0847) and question 5 (How does the artist impress you in terms of intelligence?) revealed a statistically significant F-ratio (.0568). The artist, labeled as a "girl," received the lowest rating on question 4 (purchase price), and on question 9 (what kind of future success).

The male respondents of the study rated as second highest the assumed female artist's work when she was referred to as a "woman" by a small margin over the female artist who was referred to as a "person." The margin does not seem to be statistically significant, and this mean is much lower than the label of a "girl," a preferred sexual label of the males. The artist, labeled as a "woman," received second higher ratings for question 9; the next to highest ratings for the questions 1,2 , and 5 , and the lowest rating on the questions $3,6,7$, and 8 . However, on the question 4 (Give your best estimate of purchase price) the assumed female artist, when labeled as a "woman," received the highest rating of borderline statistical significance (p-value was .0589).

The male participants rated the assumed female artist's work with the lowest mean when she was addressed as a "person," although by a very small but not statistically 
significant margin. The female artist, labeled as a "person," received her next to highest ratings for the questions $3,4,6,7,8$, and 9; she received her lowest ratings for the questions 1,2 , and 5 .

On the basis of the above information, it was revealed that there were significant statistical differences between the ratings of female and male students of the assumed female artist's work. Therefore, hypothesis 4 was rejected. Hypothesis 5

There are no statistically significant differences in perception of a male artist's work, when referred to as "man," "guy," or "person," by female and male community college and university students.

The Analysis of Variance was performed on the data collected from community college and university students, testing the entire group of participants. The resulting ratios demonstrated the absence of statistically significant differences between the perception of female and male respondents toward male sexual labels as shown in Table 11.

The ratings that the participants of both genders gave to the assumed male artist indicate that when the male artist was labeled as a "guy," he received the highest rating. When the male artist was referred to as a "guy," he received the highest rating for questions $2,6,7,8$, and 9, and second highest rating for questions $1,3,4$, and 5 . 


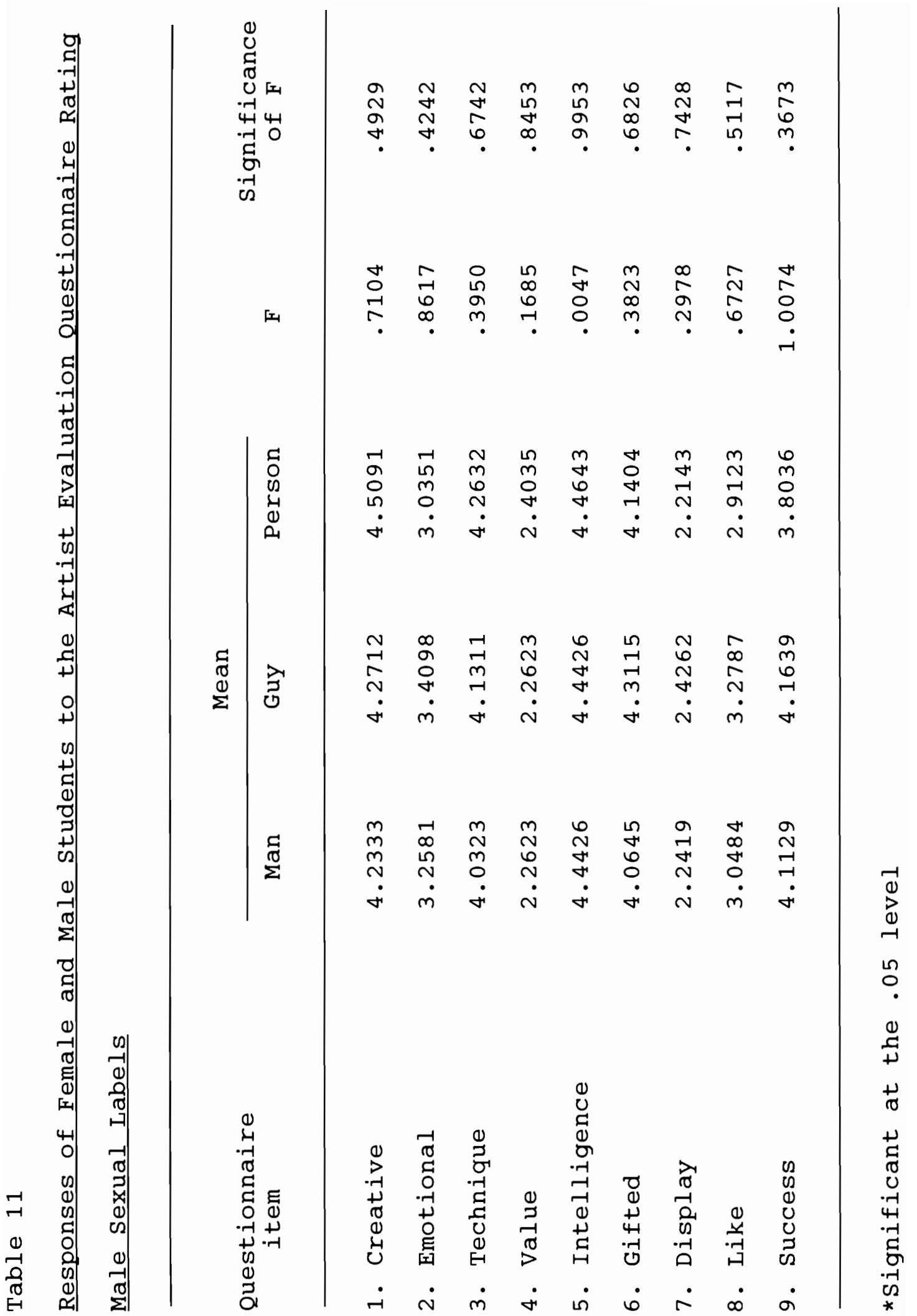


This rating, however, was not statistically significant. The F-ratios were, in every case, greater than .05 .

The responses of the students of both genders indicate that when the assumed male artist was referred to as a "person," he received the second highest rating. The items $1,3,4$, and 5 gave the assumed male artist/person the highest rating, while question 6 produced the second highest rating. The artist, when referred to as a "person," received the lowest rating of items $2,7,8$, and 9 . None of these ratios were statistically significant since the Fratio was greater than .05 .

The respondents of both genders gave the assumed male artist, when he was labeled as a "man," their lowest overall rating. The assumed male artist, when called a "man," received the following responses of each item: no highest ratings were obtained; second highest rating on questions 2 , $4,5,7,8$, and $9 ;$ and the lowest rating on questions 1,3 , and 6 . None of the F-ratios carried statistically significant differences.

On the basis of the above information there was no significant difference between the responses to the sexual labels of the assumed male artist. Therefore, hypothesis 5 was not rejected.

Hypothesis 6

There are no statistically significant differences in perception of a male artist's work, when referred to as 
"man," "guy," or "person," between female and male community college and university students.

The Analysis of Variance was performed on the data collected from the community college and university students, testing the entire group of the participants. The resulting ratios indicated the absence of a statistically significant difference between the perception of male sexual labels among the female and male participants of this study as shown in Tables 12 and 13 .

The ratings of the female students of the assumed male artist indicated that the highest score was given more frequently to the assumed male artist when he was referred to as a "guy." This low status label received the highest ratings from female respondents on questions $2,3,5,6,7$, 8, and 9, and it received the second highest ratings on questions 1 and 4 . However, none of these ratings had a statistically significant F-ratio.

The ratings of the female students of the assumed male artist indicated that the second highest ratings were given to the male artist when he was labeled as a "person." This neutral label received the highest ratings from the female participants on questions 1, 3, and 4; second highest ratings were attributed to the "person/he" label on questions 5 and 6 , and the lowest ratings were given for questions 2, 8, and 9. The F-ratio, however, was greater than .05 and was not statistically significant. 


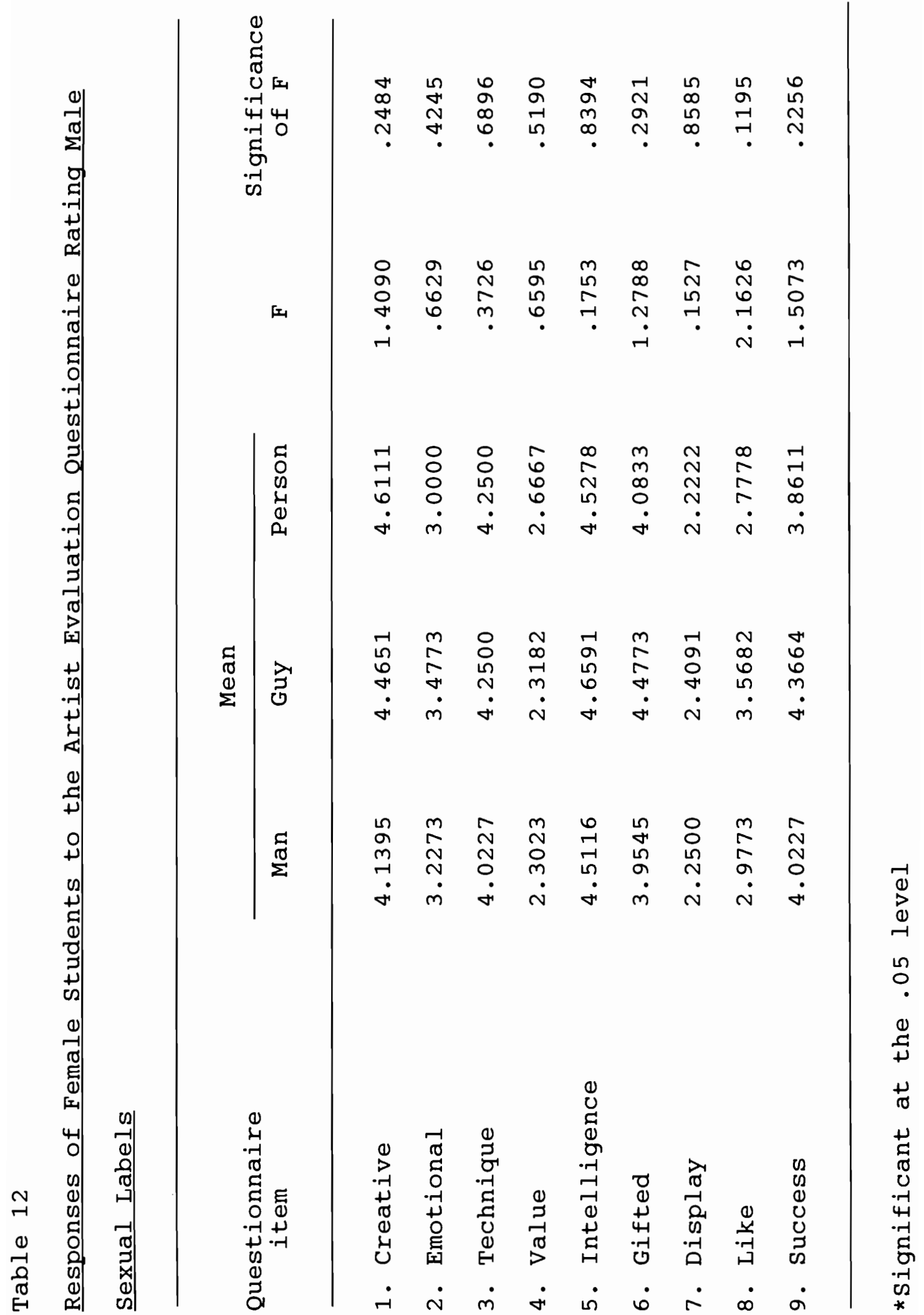




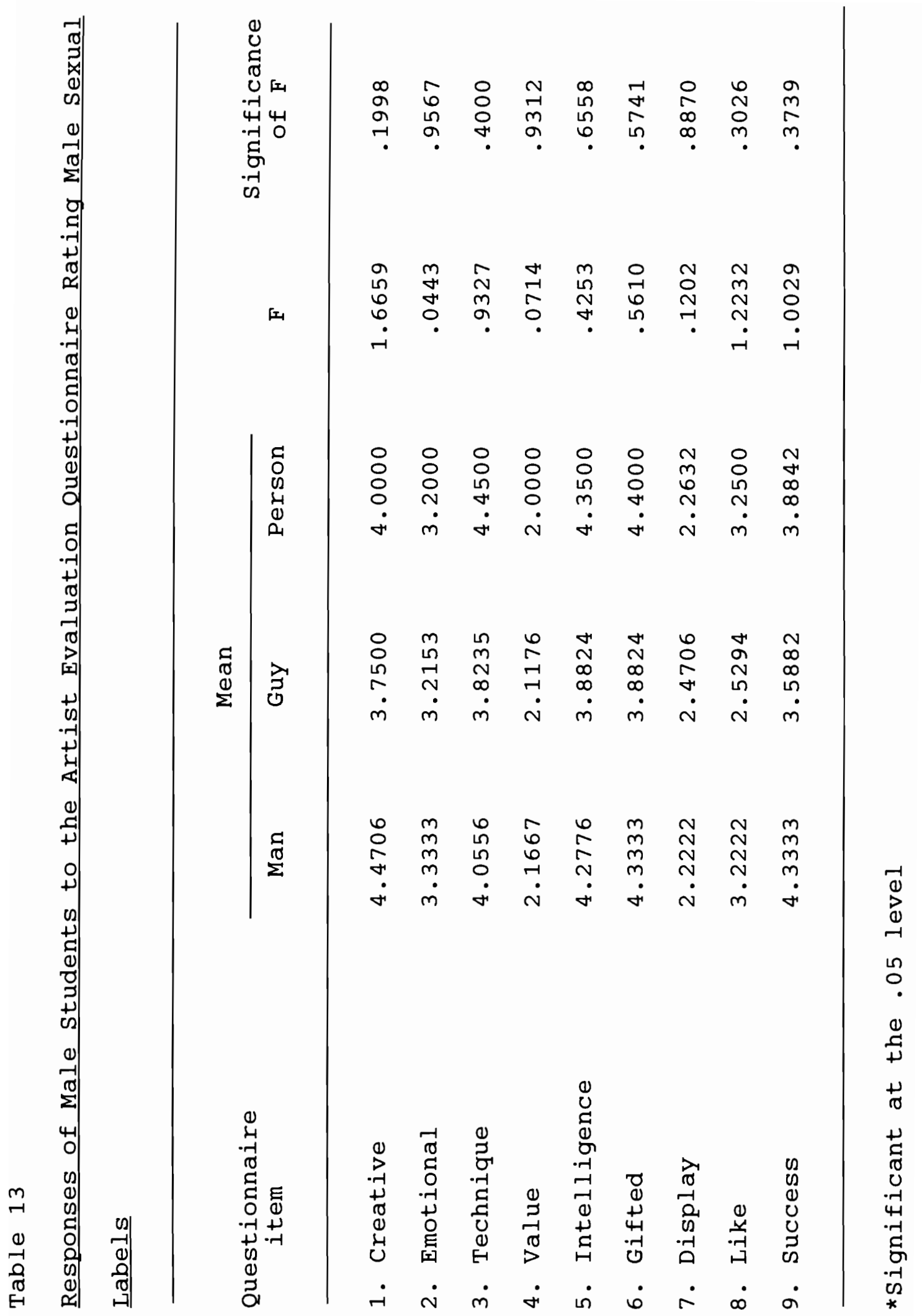


The ratings of the female respondents of the assumed male artist indicated that the lowest scores were attributed to the assumed male artist when he was referred to as a "man." The label did not receive highest ratings for any items. The second highest ratings were given to the assumed male artist when he was referred to as a "man" on questions $2,3,7,8$, and 9 . The lowest ratings were received for the high status label on question $1,4,5$, and 6 . These ratings were not statistically significant since the F-ratio remained above .05 .

The male respondents' ratings of the assumed male artist revealed that the highest rating was awarded to the assumed male artist when he was referred to as a "person;" however, this highest rating was only slightly higher than the high status label of a "man." The neutral label, "person/he," received the highest ratings on questions 1,3 , 5,6 , and 8 . the second highest ratings were revealed for questions 7 and 9 , and the lowest ratings were received for questions 2 and 4. although the label "person" was the most popular among the male students, the F-ratios were not statistically significant at the p-values greater than .05 . The second highest rating was given to the assumed male artist when he was referred to as a "man," only slightly lower than that of the "person/he." This high status label received the highest ratings from the male student son questions 2, 4, and 9; the second highest ratings were 
attributed to question $1,3,5,6$, and 8 . The lowest rating was given to questions 7 . the F-ratio was greater than .05 , and was not statistically significant.

The male participants gave the lowest ratings to the assumed male artist when he was labeled a "guy." This low status label received its highest rating on questions 7 ; second highest ratings were received for questions 2 and 4 , and the lowest ratings appeared for questions $1,3,5,6,8$, and 9. The ratio of the means were not significant since the F-ratios remained greater than .05 .

On the basis of the above information, it was concluded that a significant difference did not exist between the perceptions of the female and the male respondents that rated the male sexual labels. The female respondents rated the assumed male artist higher when referred to as a "guy;" however, this rating was not statistically significant since the F-ratios remained greater than .05 . While the male respondents rated the assumed male artist higher when referred to as a "person" or a "man," the F-ratios were not statistically significant (>.05). Therefore, hypothesis 6 was not rejected.

\section{Hypothesis 7}

There are not statistically significant differences in perception of a female and male artist's work between expressive (feminine), instrumental (masculine) or 
androgynous personalities of community college and university students.

The Analysis of Variance was performed on the data collected from the community and the university students, testing the entire group of the participants. The resulting evidence revealed the absence of expressive (feminine) and instrumental (masculine) personalities in the participating students of both genders. Only androgynous personalities were present with a range of 0 to +5 or -5 (see Table 14). The 326 participants that responded to the Attitude Questionnaire did not yield the three categories: expressive (feminine), instrumental (masculine), and androgynous. The only range present among the students was that of androgyny or none.

All of the participants fell into the personality range of androgenous; a portion was distributed into the area of near feminine androgyny and another portion fell into the area of the near masculine androgyny. However, the spread between the near feminine and near masculine androgynous personalities was statistically significant for question 9 (success), and the p-ratio was .0494 .

With the exception of question 4 (best estimate of the price of all five works), all the Artist Evaluation Questionnaire items received the largest number of responses for the value label of level 4.00 , or "average." 


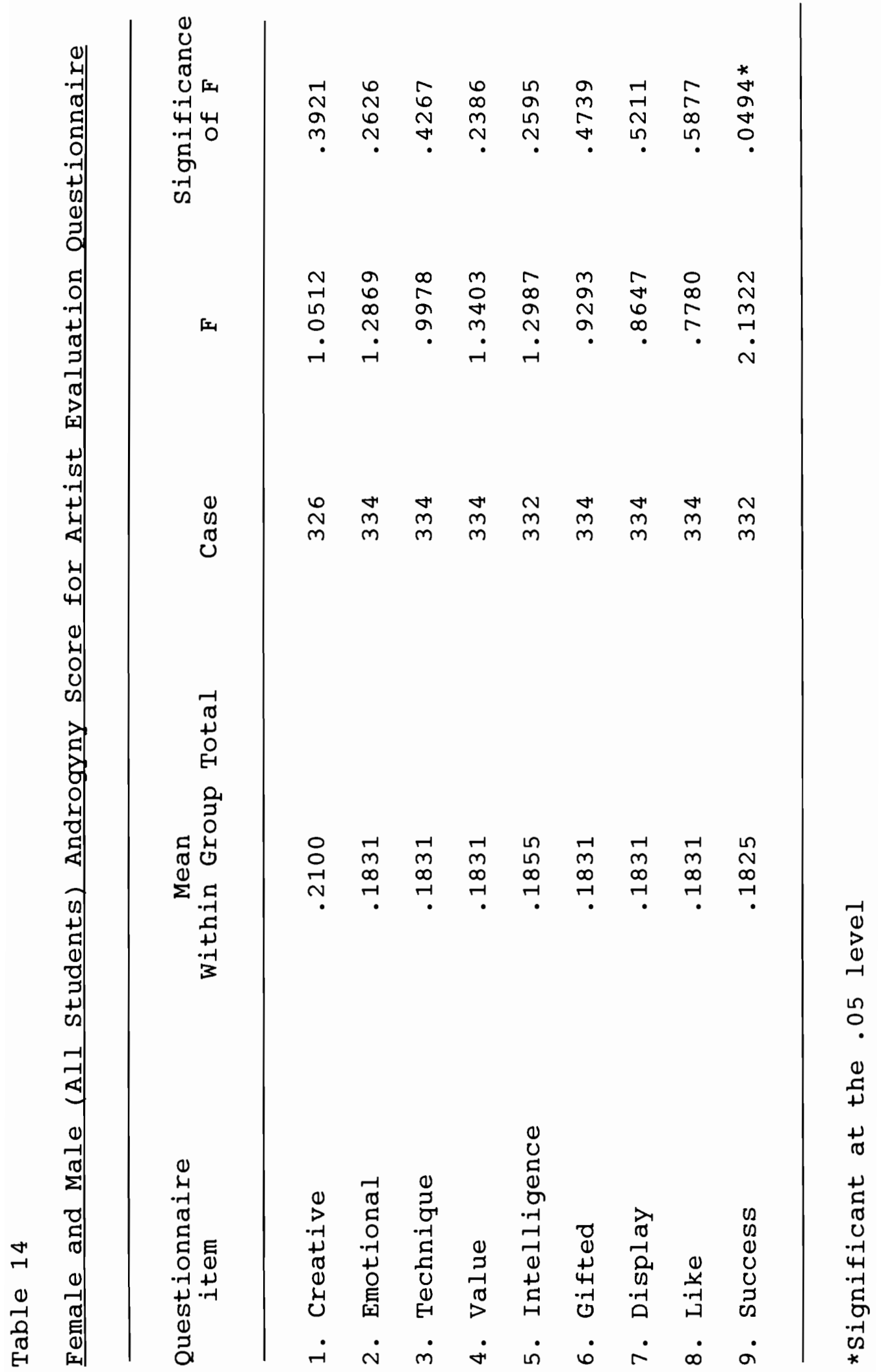


On the basis of the above information, hypothesis 7 was rejected.

Hypothesis 8

There are no statistically significant differences in perception of a female and male artist's work, between expressive (feminine), instrumental (masculine), or androgynous personalities of female community college and university students and between expressive (feminine), instrumental (masculine), or androgynous personalities of male community college and university students.

The Analysis of Variance was performed on the data collected from the community college and university students, testing the entire group of the participants. The results revealed the absence of both the expressive (feminine) and the instrumental (masculine) personality among the participants of both genders. Only the androgynous personality type was present among the participating students (see Tables 15 and 16).

The 234 participants that responded to the Attitude Questionnaire did not include either the expressive (feminine) or the instrumental (masculine) personalities; only the androgynous personality range was present, and the analysis of variance of this section of the total possible range did not yield statistically significant differences between the participants on any of the nine items of the Artist Evaluation Questionnaire. 


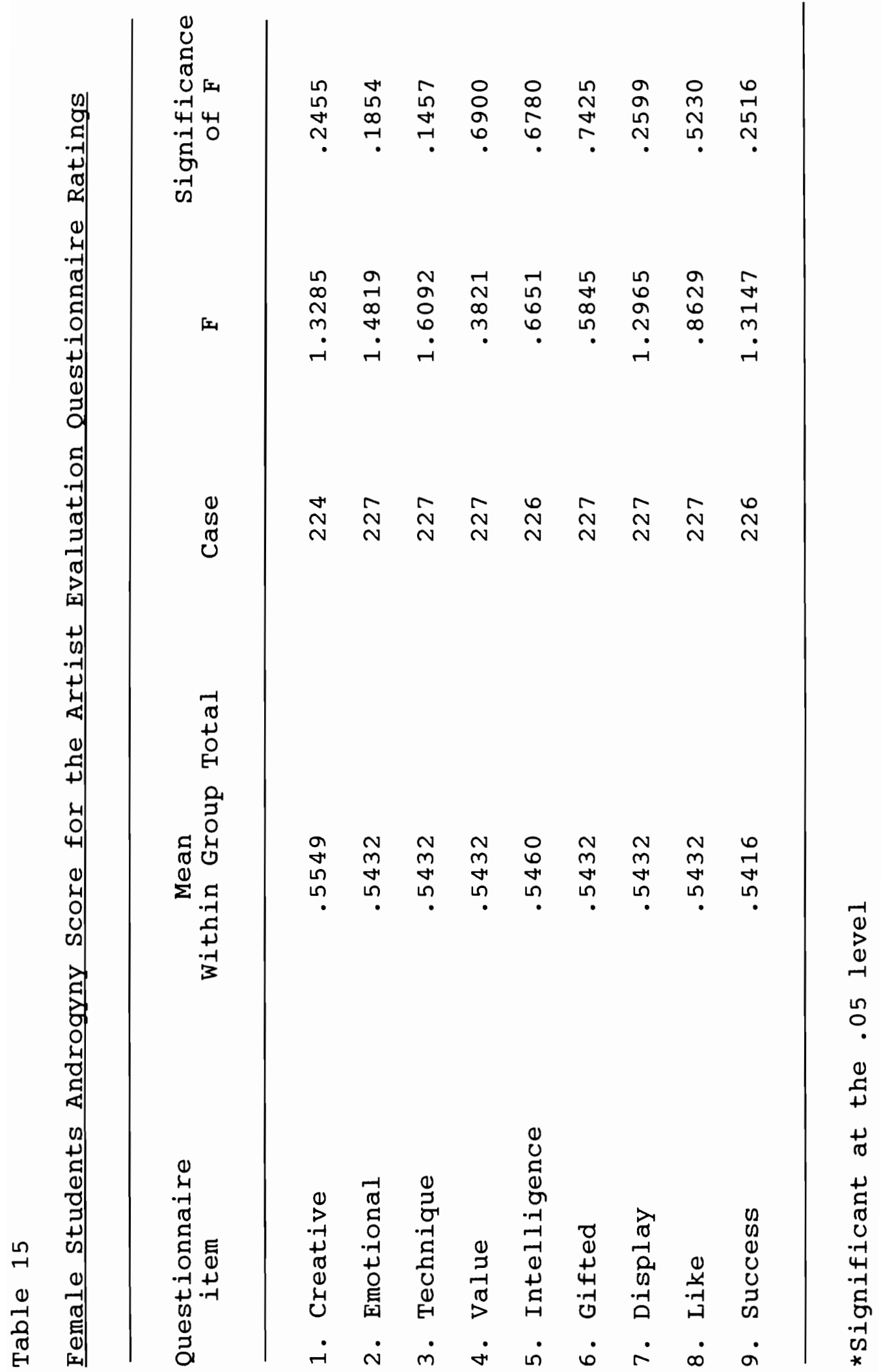




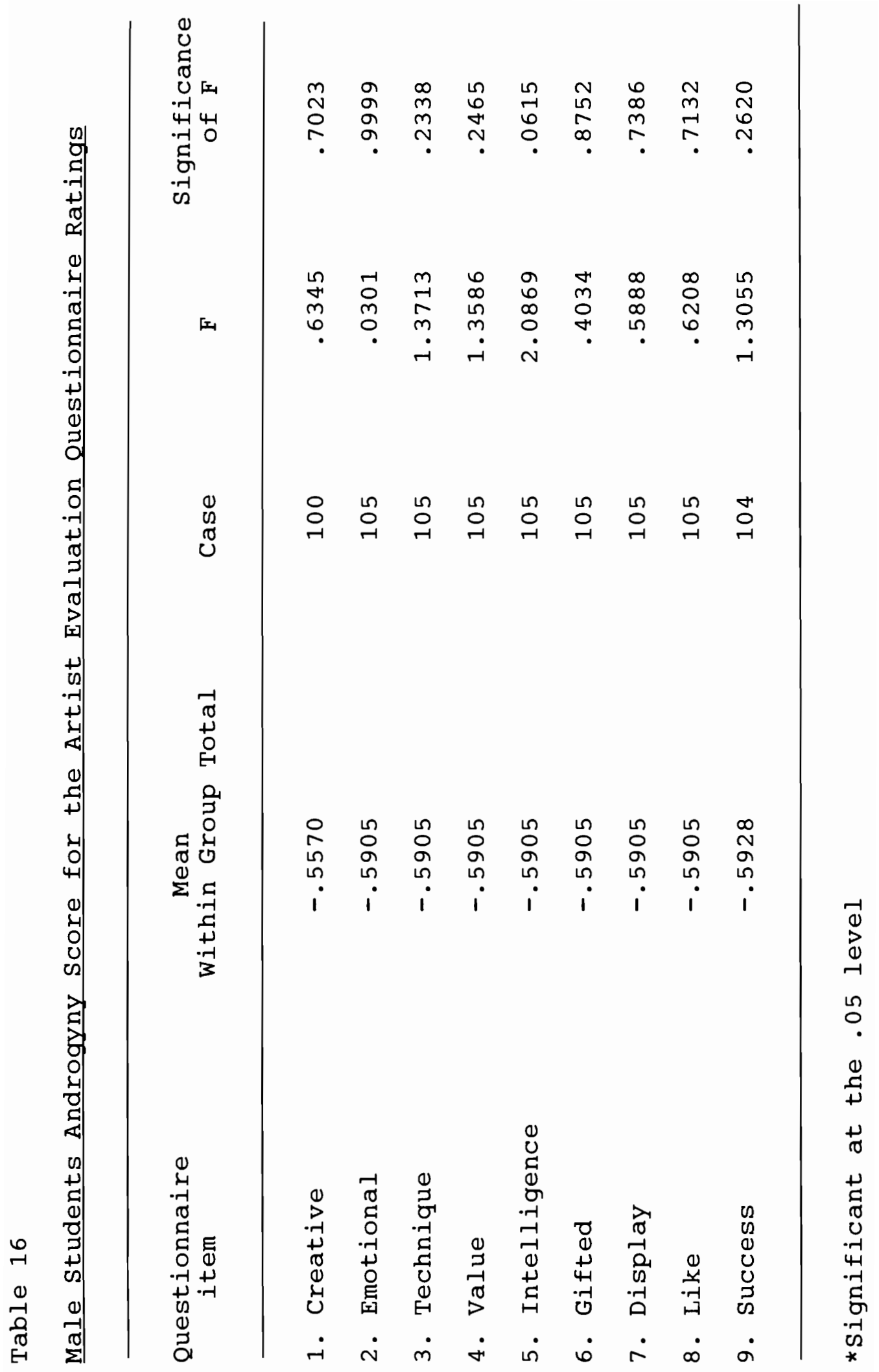


Although all the female respondents fell into the range of the androgynous personality, about half of this range was in the area of the near feminine, and a very small percentage of the personalities of the female participants was located within the range of near masculine. This data did not have statistically significant differences. With the exception of the items 4 (price), 7 (display), and 8 (like), which were evaluated low by the near feminine personalities of the female participants, the majority of the female participants answered the questions using value labels at level 4.00 (average), and these students had near feminine androgynous personalities.

It was also observed that the female participants with androgynous or near masculine personalities rated higher than the females with the near feminine personalities; however, the difference was not statistically significant. The 105 male participants that responded to the Attitude Questionnaire did not present the expected range that would include the expressive (feminine), the instrumental (masculine) and the androgynous personalities. The only statistically significant group was the androgynous personality category; a very small number of males within this population sample had an instrument (masculine) personality. This fact was reflected in question 5 (intelligence), which was of borderline significance (pvalue was .0615). 
The Analysis of Variance of the androgynous male population did not yield a statistically significant variance within the group; however, a large portion of male participants had near masculine personality characteristics. With the exception of items 4 and 7 , rated low by the near masculine personalities, the items on the Artist Evaluation Questionnaire were rated by the majority of the male participants of androgynous personalities at value label at the level 4.00 (average).

The male participants with the androgynous and the near masculine personalities were observed to evaluate somewhat higher than the female participants of this study.

The expressive (feminine) and instrumental (masculine) personalities of the participants were almost non-existent among the 326 participants that responded to the Attitude Questionnaire. Nearly all the participating students' personalities were androgynous with a range of 0 to +5 or 0 to -5 .

The androgynous personalities of the participants of both genders did not display a range that was statistically significant, although it was observed that a large portion of the female participants' personalities fell within the range of near feminine, and an even larger proportion of the male participants' personalities were located within the range of the near masculine. A very small percentage of the males (not statistically significant) fell into the range of 
a masculine (instrumental) personality. Most students with androgynous personalities tended to rate the artist as "average" most frequently.

It was observed that the female students with near female or androgynous personalities tended to rate the artist lower than the male students with the near male or androgynous personalities.

On the basis of the above information, hypothesis 8 was rejected.

\section{Summary}

A summary of the findings is shown in Table 17 for the purpose of clarity. 
Table 17

Summary of Findings

Hypothesis

Result

1. The female artist was rated higher than the male artist by all students.

rejected

2. The female and male artists were rated equally by the female students; the female artist was rated higher than the male artist by the male students.

rejected

3. The students of both genders rated all the female sexual labels equally.

not rejected

4. Female sexual labels rated by female and male students indicated that the female students preferred the neutral sexual label, "person." The male students preferred the low status female sexual label, "girl;" their second preference was the high status sexual label, "woman." Significant gender differences were found in the ratings of female sexual labels. rejected

5. Male sexual labels, when rated by both genders, did not reveal any significant statistical differences.

not rejected

6. Male sexual labels, when rated by female and male students separately, did not produce any statistically significant differences.

not rejected

7. Expressive (feminine) and instrumental (masculine) personalities were absent among the students of both genders. Androgynous personalities were present, Question 9 revealed a statistically significant spread between the near feminine androgynous and the near masculine androgynous personalities, which was statistically significant. 
8. Expressive (feminine) and instrumental (masculine) personalities were not present among the female students; same situation occurred among the male students. Only androgynous personalities were present, with some near feminine personalities located within the androgynous range for the female students, and some near masculine personalities positioned within the androgyny range for the male students. rejected 


\section{CHAPTER V}

Summary, Conclusions and Recommendations

\section{Summary}

The purpose of this study was to investigate and determine whether community college and university students displayed sexist behaviors in affective and cognitive domains when perceiving works of art by female and male artists, and whether sexual labels, attached to the artists, determined the affective and cognitive perceptions of these students.

The researcher's discipline, art history, as presented and interpreted within the current higher education system, reflects a bias toward the female gender, like the rest of the education curricula at college and university levels. Although scholarly research in the area of gender inequities in education has begun, it is still comparatively new. Very few of the studies on gender issues relate directly to the area of art.

It is critical to examine the use of linguistic rules and terminology, employed by the higher education system in order to first comprehend, and then modify the existing gender-biased behaviors. This society and its educational systems, the use of language is often based on various assumptions and attitudes about gender roles. Many scholars 
contend that we must consciously rid our language of sexist terminology and connotations, in order to achieve equal educational and social goals for both genders. This study attempts to clarify these concerns, by examining the use of sexual labeling within the area of higher education.

Sexual labeling was the subject of a study by Lipton and Hershaft (1984). The effect of sexist labeling on 60 female and 60 male college level students was investigated. Students viewed slides of art works by assumed female and male artists, and were asked to express their opinions about these works. The results of that study revealed that both the high status label (woman) and the low status label (girl) produced negative effects on the subjects' judgments of the female artist's work. For the male artist, both the low status label (guy) and the high status label (man) had equally positive effects on the subjects' judgments. No differences were observed between the judgments of the female and male subjects.

This study was inspired by the Lipton and Hershaft (1984) research. It was designed to investigate the effects of sexual labeling, related to art works, and whether it would vary because of the gender of the subjects. The study also attempted to determine if the subjects' sex role orientation, as outlined by the Bem Sex Role Inventory (BSRI) questionnaire, called the Attitude Questionnaire, would affect the subjects' judgments. The possible 
personality characteristics were defined as expressive (feminine), instrumental (masculine), or androgynous. The hypotheses of this investigation have been restated as purposes of the study for clarity, as follows:

1. Determine whether there were any differences in perception of a female and a male artist's work, by all the community college and university students, regardless of their gender.

2. Identify any differences in perceptions of a female or male artist's work between female and male community college and university students.

3. Determine whether there were differences in perception of a female artist's work, when referred to as woman (high status label), girl (low status label), or person (neutral label), by both female and male community college and university students.

4. Determine whether there were differences in perception of a female artist's work, when referred to as a woman (high status label), girl (low status label), or person (neutral label), between female and male community college and university students.

5. Identify whether there were differences in perception of a male artist's work, when referred to as man (high status label), guy (low status label), or person (neutral label), by female and male community college and university students. 
6. Determine whether there were differences in perception of a male artist's work, when referred to as a man (high status label), guy (low status label), or person (neutral label), between female and male community college and university students.

7. Identify whether there were differences in perception of a female and male artist's work between expressive (feminine), instrumental (masculine), or androgynous personalities of community college and university students.

8. Determine whether there were differences in perception of a female and male artist's work between expressive (feminine), instrumental (masculine), or androgynous personalities of female community college and university students, and between expressive (feminine), instrumental (masculine), or androgynous personalities of male community college and university students.

\section{Procedures}

In order to make the above comparisons, eight null hypotheses were developed. The cover letter, instructions, six versions of an artist's brief biography with imbedded sexual labels (woman, girl, person/she, man, guy, person/he), the Artist's Evaluation Questionnaire, and the Demographic Questionnaire were also developed. The Bem Role Inventory (BSRI) named for this study the Attitude Questionnaire, was also used. All these were arranged into 
a packet that was distributed to a total of 370 community college and university students who were asked to complete the questionnaires after viewing the five slides of an artist's work. Analysis of variance testing was applied to the data generated by the study population sample. The results of the statistical testing applied to the data revealed that statistically significant differences existed among the group mean scores of hypothesis 1, hypothesis 2, hypothesis 4, Hypothesis 7, and hypothesis 8. Statistically significant differences were not obtained from the mean scores of hypothesis 3, hypothesis 5, and hypothesis 6 . In testing hypothesis 1 , it was found that all community college and university students evaluated the female artist's work higher than the assumed male artist's work. This difference in ratings was not always large enough to be statistically significant. The rating of question 2 (Is this artist's work emotionally appealing to you?) yielded borderline statistical significance, and question 9 (In your opinion, what kind of future is this artist capable of achieving?) revealed a ratio that was statistically significant.

When hypothesis 2 was tested, it was revealed that the female community college and university students perceived the assumed female and the assumed male artist's work differently from the male community college students. Although the female participants of the study rated the 
female artist slightly higher than the male artist on all nine questions, the difference in the mean ratios was not statistically significant. The responses of the male college and university students indicate that they rated the assumed female artist's work higher on all nine items. Question 2 (Is the artist's work emotionally appealing?) and question 3 (In your opinion, how competent is this artist in terms of the technique of painting?), question 4 (These five paintings were purchased by the Art in Public Places Program. Please give your best estimate of the purchase price/vale of all five works), and question 6 (How gifted/ possessing natural artistic ability does this artist seem to be, according to your perception?) did not produce statistically significant mean ratios. The rest of the questions revealed statistically significant mean ratios. They were: question 1 (In your personal opinion, how creative is this artist?), question 5 (In your opinion, how does the artist impress you in terms of intelligence?), question 7 (Would you be willing to display this artist's work at your own home?), question 8 (How much do you like this artist, judging from the work seen?), and question 9 (In your opinion, what kind of future success is this artist capable of achieving?) .

The statistical testing of hypothesis 3 disclosed that when all the students (both genders) evaluated the work of the assumed female when referred to as "woman" (high status 
sexual label), "girl" (low status sexual label), or "person/she" (neutral label), no statistically significant differences were found in question 1 to 9 , although question 8 displayed a borderline significance in favor of a neutral label, person. Hypothesis 3 was not rejected.

The statistical testing of hypothesis 4 revealed that the sexual labels of woman (high status), girl (low status), and person/she (neutral), generated different responses, depending on the gender of the participant. The gender differences produced statistically significant results. The responses of the female participants indicated that the gender neutral label, "person," received the highest ratings. When referred to as a person, the female artist received highest ratings on questions 1 though 8 , and second highest on question 9 (future success). Only question 8 (How much do you like this artist, judging from the work seen?) recorded a statistically significant mean ratio. Among the male students, the low status sexual label of a "girl" was preferred. The female artist received her highest overall ratings when she was referred to as a "girl," with the exception of question 4 (price) and question 9 (success); however, not all of them were statistically significant. Question 1 (How creative is the artist?) and question 5 (How does the artist impress you in terms of intelligence?) displayed the mean ratios of statistical significance. 
The results of the statistical testing of hypothesis 5 indicated that when the assumed male artist was referred to as a "man" (high status sexual label), "guy" (low status sexual label), or "person/he" (neutral label), the mean ratios of the ratings of the students of both genders did not reveal significant statistical differences. This hypothesis was not rejected.

The male sexual labels of man (high status), guy (low status), and person/he (neutral) were also tested for hypothesis 6. The assumed male artist's work was not perceived differently when the sexual labels were used. The statistically significant ratios between the means of the ratings of both genders were not revealed in testing this hypothesis, and it was not rejected.

The testing of hypothesis 7 , with the intent to determine the effect of the feminine (expressive), masculine (instrumental), and androgynous personalities on the ratings of the female and male artists revealed the fact that college and university students' personalities did not include any feminine or masculine personality types. The masculine personality type existed only marginally, and was not statistically significant. Question 9, however, revealed a statistically significant mean ratio due to the spread of the near feminine and the near masculine androgynous personalities. Due to the fact that all the 
statistical analyses were administered to one personality type, androgynous, hypothesis 7 was rejected.

The examination of the ratios of hypothesis 8 demonstrated that 2 out of 3 personality types to be investigated, the feminine (expressive) and the masculine (instrumental) existed only marginally among the students of both genders. Since the feminine and the masculine personality types were not statistically present, all the analysis was confined to the examination of one type of personality, androgynous, among both the female and the male genders. Therefore, it was decided that hypothesis 8 should be rejected.

\section{Conclusions}

The results of this study provide information that seems to be consistent with the direction of the recent research that deals with the issues of art, society, higher education, and the linguistic impact on perceptions of gender roles. Perhaps the most important issue that emerged from this study was the fact that there were differences in the perceptions of the genders.

This study was inspired by the Lipton and Hershaft (1984) study that investigated the effects of sexual labeling. Similar questions were asked the students in that study, using the same set of sexual labels for the assumed female and the assumed male artist. The results of that study did not show statistically significant differences 
between the opinions of the female and male participants. The study showed that the male artist's work was rated significantly higher than the female artist's work on the question regarding the estimated value of the painting. The male artist's paintings were also rated significantly higher than the female artist's paintings on the question regarding creativity of the artists. The male artist's paintings were rated significantly higher than the female artist's paintings on the question of whether they were emotionally moving.

There was also a significant mean ratio between the sex of the artist and the artist's label. The male artist's work was rated significantly higher when he was labeled a man (high status) or guy (low status), but dropped below the female artist when he was referred to as a person (neutral label) on the question of the potential career success. In the case of the male artist's work, the use of the neutral label devalued his work; the opposite held true for the female artist. The neutral label gave the artist her highest rating for the same question, while the use of the labels of woman (high status) and girl (low status), placed her ratings significantly below those of the male artist's. It is important to note that the female artist's work earned as high a rating as a male artist's work when she was labeled a person (sex neutral label). 
In this study, which was partially a replication of the Lipton and Hershaft's (1984) study of approximately nine years ago, one factor remained the same regarding the female participants: the neutral label, "person," earned the highest ratings with the female gender. However, only on question 8 (How much do you like this artist?) did the female participants rate the female artist/person significantly higher than when labeled as a "woman" or a "girl." The male participants did not express their preference for the gender-neutral label; in fact, they liked it the least.

While female students preferred the neutral sexual label for their own sex, they did not express any preference for the sexual labeling of the male artist's work; however, there was a small, non-significant preference toward the low status label, "guy."

The male respondents of the study gave the female artist's paintings highest ratings when she was called by a low status sexual label, a "girl." The artist/girl received the highest ratings from the male participants on questions $1,2,3,5,6,7$, and 6 . On question 1 (How creative is the artist?) and on question 5 (How does the artist impress you in terms of intelligence?) this difference is clearly significant. The male participants expressed preference for the high status sexual label, "woman," when confronted with question 4 (Give your best estimate of the purchase price). 
The neutral label, "person/she," did not produce any statistically significant mean ratios from the male participants of the study. The male participants of the study, just like the female participants, did not have any preference for any of the male sexual labels. The ratios of the labels did not produce any significant preferences when applied to the male artist's work.

A new gender difference also became apparent when the ratings of the female and the male participants were compared. When the comparison between the means of the female participants and the means of the male participants' ratings were made, it became apparent that the female participants rated both the female and the male artist's paintings lower than the male participants. It was also observed that the female participants' ratings did not reveal a statistically significant preference of one artist's gender over the other.

This investigation revealed that the male participants of the study had a tendency to give higher ratings. The male participants also rated the female artist's paintings higher than those of the male artist. This difference in ratings was statistically significant for question 1 (In your personal opinion, how creative is the artist?), question 5 (In your opinion, how does the artist impress you in terms of intelligence?), question 7 (Would you be willing to display this artist's work at your own home?), question 8 
(How much do you like this artist, judging from the work seen?); and question 9 (In your opinion, what kind of future success is this artist capable of achieving?).

These findings are consistent with other recent studies that discovered gender differences in perceptions. Several recent studies within the disciplines of art, education, and sociology had investigated the various gender differences in relation to cognitive and affective stimuli. Ellenbecker and King (1990) did a study on visual art studio classes of university students on the effects of mood changes induced through artistic expression. The authors concluded that the males exhibited increased responsiveness toward the art process, which increased as the semester progressed. The male students also displayed increase in self-efficacy. This was not true for the female students. A study in gender differences in drawings was performed on school children by Silver (1992) that also demonstrated gender differences in perceptions of the task. The resulting drawings showed that twice as many boys as girls drew images of autonomous subjects that were engaged in pleasurable activities and were enjoying themselves.

This study revealed significant differences in perceptions of sexual labels by the female and male students. The female students clearly favored the neutral label of a "person" for the female artist. This finding may have indicated an effect of the current educational system 
that may promote sexism in female students. The female student may feel threatened by her gender. She sees her gender devalued, and may feel more comfortable with the label that does not mark her as an individual of the oppressed sex. The negative connotations of female sexual labels may have been perceived by the female students, regardless of whether the labels are a high or low status. The preference for the neutral label in female students may also indicate the fear of being, to be discriminated against or to see their gender being discriminated against. Also, it may indicate the possibility of psychological alienation of a female student from her gender, or a symbolic denial of her gender.

This study did not reveal any statistically significant preferences for the sexual labeling of the assumed male artist in both female and male students. It can be observed that when one gender occupies superior or dominant status in a society and its educational system, all the sexual labels, whether high status, low status or neutral, do not diminish an individual's value in that society.

The male students of this study favored the low sexual label "girl" for the female artist. It seems that males may have a vested interest in perpetuating the low status labels for females, since they promote social submission of the female gender. It is also possible that this labeling preference of male students is a result of a habit, since 
the label is frequently used in discourse, television and other media. Many college and school textbooks also perpetuate sexist language. Montana (1990) contends that our linguistic model plays a primary role in influencing "students' perceptions of the world" (p. 56).

Perhaps the most unexpected aspect of this study was revealed when male students consistently rated the female artist's paintings higher than the male artist's. This fact is not inconsistent with previous studies, which demonstrated higher ratings or higher levels of performance or of optimism from the male gender. Thomas and King (1990) reported that their study showed that "it appeared that male subjects generally increased their sense of self-efficacy over fourteen weeks of studio art class, while females actually decreased their confidence in their ability over the same time period" (p. 108).

It may be possible that the higher ratings for the female artist's work from male students were the result of a general sense of self-assurance that male students seem to exhibit more frequently in classes; another reason may be the fact that the artist was not perceived as an historical or major figure, but as an average contemporary artist. On a more ordinary level, artists are not regarded as high level success figures or role models, and most earn only a modest living. Statistics show that approximately $50 \%$ of artists are female. It is very acceptable for a female 
student to be an aspiring artist, and about $75 \%$ of college students that are art majors are females. Art, as a low paying profession, may have been perceived more suitable for a female. Artists are also viewed by society as sensitive human beings that are guided by their emotions rather than their rationality, a concept that often applies to women. Male students may have been guided by these values when rating the female artist, and may have perceived her as more appropriate for the role than the male artist.

The study also unfolded the fact that most students had androgynous personalities, according to the result of the BSRI scores. This seems to indicate that a balance of the expressive and instrumental characteristics was present in both genders. It was clear that a feminine (expressive) or a masculine (instrumental) personality is not adaptable enough to function successfully within the current system of higher education, or, by implication, within our societal environment, and that in order to function successfully, both characteristics must be present in an individual.

\section{Implications}

The results of this study indicate that female sexual labeling affected the perceptions of students that participated in this study. The study showed that there were gender differences in the perceptions of the students, and that the prevalent sex role personality of a student was androgynous. 
This study indicated that positive changes have been made since the previous gender studies of several years ago. Although the sexual labeling affected the perceptions (and seemingly self-concept) of the female students, both genders appeared to be much less biased toward the female gender (female artist received either equal or higher evaluations than those of the male artist). Karner (1991) found similar situations in her study conducted to determine the significance of gender as a stigmatic social label in the discipline of art. The 112 students of Karner's population sample rated 10 historical women artists that were presented as either male or female; both assumed genders were given equal ratings.

This investigator believes that the fact that the population sample of this study rated the assumed female artist's work equally high or higher than the work of the assumed male artist is indicative of a positive social change in attitude toward women.

\section{Recommendations}

Continuation of this investigation is recommended with a larger population sample, possibly of 300 individuals per label, or 1,200 individuals total. This may bring into focus many implications that were only suggested by this study, such as the marginal preference of low status sexual label among women participants as the second choice label after the neutral, or "person/she;" or the marginal 
preference of the low status label, "guy," for the male artist among the female students. It would also further clarify whether the male students' slight preference of the high status label, "woman" as their second choice, could be significant.

This investigator believes that further inroads into non-sexist use of language is paramount in order to further eliminate sexual stereotyping in higher education, and continued research should take place to improve the existing sexist teaching instruments.

This investigator also recommends the removal of sexist terminology of feminine and masculine from the Attitude Questionnaire. New terms, expressive instead of feminine and instrumental instead of masculine, seem to be more appropriate and less stereotypical. Perhaps the resulting sex role inventories would be somewhat more precise. 
REFERENCES

American Council on Education. (1972). Staff of the Office of Research. "The American freshman national norms for fall 1972." ACE Research Reports. Washington American Council on Education.

APA task force on issues of sexual bias in graduate education: Guidelines for nonsexist use of language. (1975). American Psychologist, 30, 682-684.

Aronoff, D. N., \& McCormick, N. B. (1990). Sex, sex role identification, and college students' projective drawings. Journal of Clinical Psychology, 46, 460-466.

Ashby, M. S., \& Witmaler, B. C. (1978). Attitude changes in children after exposure to stories about women in traditional or nontraditional occupations. Journal of Educational Psychology, 70, 945.

Bartl, J. (1975). Dick and Jane as victims: Stereotyping in children's readers. Woman on Words and Images. Princeton, NJ.

Bayer, A. E. (1975). Sexist students in American colleges: A descriptive note. Journal of Marriage and the Family, 37, 391-397.

Bem, S. L. (1985). Sex-role adaptability: One consequence of psychological androgyny. Journal of Personality and Social Psychology, 31, 634-643.

Bem, S. L. (1981). Bem sex-role inventory: Professional manual. Palo Alto, CA: Consulting Psychologists Press, Inc.

Bem, S. L. (1974). The measurement of psychological androgyny. Journal of Consulting and Clinical Psychology, 24, 155-162.

Black, M., \& Coward, R. (1981). Linguistic, social and sexual relations: A review of Dale Spender's Man Made Language. Screen Education, 19 .

Broude, N., \& Gerrard, M. D. (1982). Feminism and art history. New York: Harper \& Row.

Broverman, I. D., Broverman, D. M., Clarkson, F. E., Rosenkrantz, P. S., \& Vogel, S. R. (1970). Sex-role 
stereotypes and clinical judgments of mental health. Journal of Counseling and Clinical Psychology, 34, 1-7.

Bruch, K. (1987, July). Summary of New York City major museum exhibitions. New York: Women's Caucus for Art/New York City Chapter.

Cameron, D. (1985). What has gender got to do with sex? Language and Communication, $\underline{5}, 19-27$.

Cameron, D., \& Coates, J. (1985). Some problems in the sociolinguistic explanation of sex differences. Language and Communication, $\underline{5}, 143-151$.

Campbell, J. (1972). Myths to live by. New York: Bantam Books.

Chadwick, w. (1990). Women, art and society. London: Thames and Hudson, Ltd.

Chapman-Grant, L. (1978). Anger to action: A sex discrimination guide. Corvallis, Oregon: Women's Caucus for Art Affirmative Action Committee.

Daly, M. (1984). Pure lust: Elemental feminist philosophy. Boston: Beacon Press.

Dayhoff, S. A. (1983). Sexist language and person perception: Evaluation of candidates from newspaper articles. Sex Roles, 9, 527-539.

Deaux, K., \& Emswiller, T. (1974). Explanations of successful performance on sex-linked tasks: What is skill for the male is luck for the female. Journal of Personality and Social Psychology, 29, 80-85.

de Beauvoir, S. (1974). The second sex. New York: Vintage Books, a Division of Random House.

De La Croix, H., Tansey, R. G., \& Kirkpatrick, D. (1991). Gardner's art through the ages. San Diego: Harcourt Brace Jovanovich.

Dickinson, E. (1990). Gender discrimination in the art field. Washington, DC: National Office, Artist's Equity Association, Inc.

Diop, C. A. (1978). The cultural unit of Black Africa. Chicago, IL: Third World Press.

Dutton, B. P. (1975). Indians of the American Southwest. Englewood Cliffs, NJ: Prentice Hall, Inc. 
Eggan, F. (1985). Comparative social organization. Handbook of North American Indians. Washington, DC: Smithsonian Institution.

Eisler, R. (1987). The chalice and the blade. San Francisco: Harper \& Row.

Ellenbecker, T., \& King., A. (1990). The effects of gender and college major on mood state changes induced through artistic expression. The American Journal of Art Therapy, 28, 106-110.

Erikson, E. H. (1968). Identity, youth and crisis. London: Faber \& Faber.

Federbush, M. (1971). Let them aspire. Washington, DC: Committee to Eliminate Sex discrimination in Public Schools, Ann Arbor, Michigan.

Fine, E. H. (1978). Women and art: A history of women painters and sculptors from the Renaissance to the 20th century. London: Allanheld \& Schram/Prior, Montclair.

Fishel, A., \& Pottker, J. (1977). National politics and sex discrimination in education. New York: Praeger Publishers.

Friedan, B. (1983). The feminine mystique. New York: Bantam Doubleday Dell Publishers Group.

Gardner, H. (1971). Art through the ages. San Francisco: Harcourt Brace Jovanovich.

Giacomini, M., Rozee-Koker, P., \& Pepitone-Avieola-Rockwell, F. (1986). Gender bias in human anatomy textbook illustrations. Psychology of Women Quarterly, 10, 413420 .

Gilbert, R. (1992). Living with art. New York: McGrawHill, Inc.

Gilligan, C. (1982). In a different voice: Psychological theory and women's development. Cambridge, MA: Harvard University Press.

Gimbutas, M. (1991). The civilization of the goddess. San Francisco: Harper \& Row, Publishers.

Gimbutas, M. (1989). The language of the goddess. San Francisco: Harper \& Row, Publishers. 
Gimbutas, M. (1983). Goddesses and gods of old Europe. San Francisco: Harper \& Row.

Gladwin, H. (1985). Marking sex roles: Cognition and politics as seen through a well known riddle. Miami, FL: Florida International University, women's Studies Colloquium.

Gombrich, E. J. (1972). The story of art. Englewood Cliffs, NJ: Prentice-Hall, Inc.

Gottredson, L. S. (1981). Circumscription and compromise: A developmental theory of career aspirations. Journal of Counseling Psychology, 26, 545-579.

Gould-Davis, D. E. (1971). The first sex. New York: G. P. Putnam's Sons.

Harris, A. S., \& Nochlin, L. (1976). Women artists: 15501850. New York: Alfred A. Knopf.

Harris, T. L., \& Reiko, S. (1990). Sex-role orientation and personal adjustment. Journal of Sexual Behavior and Personality, $\underline{5}, 473-479$.

Heller, N. G. (1987). Women artists: An illustrated history. New York: Abbeville Press Publishers.

Hoffman, L. (1982). Empirical findings concerning sexism in our schools. Corrective and social Psychiatry and Journal of Behavior Technology Method and Therapy, 24, 100-108.

How schools shortchange girls: A study of major findings in girls and education. (1992). The AAUW Educational Foundation and The Wellesley College Center for Research on Women.

Janson, H. W. (1971). History of art. New York: Prentice Hall.

Janson, H. W. (1991). History of art. New York: Abrams.

Karner, T. X. (1991). Gender and evaluation in fine art. Mid-American Review of Sociology, XX, 53-69.

Katz, J. B. (Ed.) (1977). I am the fire of time: The voices of Native American women. New York: E. P. Dutton.

Kelly, J. A., \& Woreil, J. (1977). New formulations of sex roles and androgyny: Critical review. Journal of Consulting and Clinical Psychology, 45, 1101-1115. 
Kluckhohn, C., \& Leighton, D. (1979). The Navajo. Cambridge, MA: Harvard University Press.

Lippard, L. R. (1983). Overlay contemporary art and the art of prehistory. New York: Pantheon Books.

Lipton, J. P., \& Hershaft, A. M. "Girl," "woman," "guy," "man:" The effects of sexist labeling. Sex Roles, 10, 183-194.

Maclead, J. S., \& Silverman, S. T. (1973). 'You won't do' what textbooks on U.S. government teach high school girls. Pittsburg, PA: Know Inc.

Maxwell, J. A. (Ed.). (1978). America's fascinating Indian heritage. The Reader's Digest Association, Inc.

McConnell-Ginet, S. (1984). The origins of sexist language in discourse. Annals of the New York Academy of Sciences, 433, $123-135$.

Montana-Turner, R. (1990). Gender-related considerations for developing the text for art instructional materials. Studies in Art Education, 32, 55-64.

Morgan, L. W. (1975). League of the Iroquois. Seacaucus, NJ: The citadel Press.

The National Council of Teachers of English. (1977). Printed in U.S.A.

National Endowment for the Arts. (1983, July 4). Research Division, Note No. 4 .

Nochlin, L. (1988). Women, art, and power and other essays. New York: Harper \& Row, Publishers.

Olin, F., \& Brawer, C. C. (1988). Career markers. Making their mark: Women artists move into the mainstream, 197085. R. Rosen, curator. New York: Abbeville Press Publishers.

Opler, M. W. (1985). The Apachean culture pattern and its origins. Handbook of North American Indians. Washington, DC: Smithsonian Institution.

Orenstein, G. F. (1990). The reflowering of the goddess. New York: Pergamon Press

Otten, C. M. (1971). Anthropology and art. Garden City, NY: The National History Press, Introduction. 
Parker, R., \& Pollock, G. (1980). Old mistresses women, art and ideology. New York: Pantheon Books.

Perdue, V. P., \& Connor, J. M. (1978). Pattern of touching between preschool children and male and female teachers. Child Development, $\underline{49}, 1258-1262$.

Petersen, K., \& Wilson, J. J. (1978). Women artists recognition and reappraisal from early middle ages to the twentieth century. New York: Harper \& Row Publishers.

Peterson, C. C., Lawrence, J. A., \& Dawes, I. (1990). The relationship of gender, sex role, and law-and-order attitudes to nuclear opinions. Sex Roles, 22, 283-292.

Pheterson, G. I., Kiesler, S. D., \& Goldberg, P. A. (1971). Evaluation of the performance of women as a function of their sex, achievement, and personal history. Journal of Personal and Social Psychology, ㄴ, 114-118.

Quackenbush, R. L. (1990). Sex roles and social-sexual effectiveness. Social Behavior and Personality, 18, 3540 .

Sieber, R. (1971). The arts and their changing social function. In Anthropology and Art, Charlotte M. Otten, Editor. Garden City, NY: The Natural History Press.

Silver, R. (1992). Gender differences in drawings: A study of self-images, autonomous subject, and relationships. Art Therapy: Journal of the American Art Therapy Association, $\underline{9}, 85-92$.

Slatkin, w. (1985). Women artists in history from antiquity to the twentieth century. Englewood Cliffs, NJ: Prentice-Hall, Inc.

Smith, K. C., Ulch, S. E., Cameron, J. E., Cumberland, J. A., Musgrove, M. A., \& Tremblay, N. (1989). Genderrelated effects in the perception of anger expression. Sex Roles, 20, 487-500.

Spence, J. T., Helmreich, R., \& Holahan, C. K. (1974). Negative and positive components of psychological masculinity and femininity and their relationships to self-reports of neurotic and acting-out behaviors. Journal of Personality and Social Psychology, 37, 16731682 .

Stanley, J. P. (1977). Gender-marking in American English: Usage and reference. Sexism and Language. National council of Teachers of English. 
Statistics Programs Information Tabulations. (1989). A gender publication of spit ink. Compiled by school/department contact, Autumn 1989.

Stockard, J. (1980). Sex equity in education. New York: Academic Press.

Stone, M. (1976). When God was a woman. San Diego, New York, London: Harcourt Brace Jovanovich, Publishers.

Tufts, E. (1984). American women artists, past and present, a selected bibliographic guide. New York and London: Garland Publishing, Inc.

Tufts, E. (1974). Our hidden heritage: Five centuries of women artists. Paddington Press, Ltd.; distributed by Grosset \& Dunlap.

University of State of New York. (1975). Reviewing curriculum for sexism. New York: The state Education Department.

Walker, B. G. (1985). The crone. San Francisco: Harper \& Row, Publishers.

Walker, B. G. (1983). The woman's encyclopedia of myths and secrets. San Francisco: Harper \& Row, Publishers.

West, C., \& Zimmerman, D. H. (1977). Women's place in everyday talk: Reflections on parent-child interaction. Social Problems, 24, 521-529.

West, C. (1979). Against our will: Male interruptions of females in cross-sex conversation. Language, Sex and Gender: Does "La Difference" Make a Difference? (pp. 8197). J. Orasanu, M. K. Slater, \& L. L. Adler, Eds. New York Academy of Science.

White, B. E., \& White, L. S. (1973, January). Women's caucus of the college art association survey of the status of women in 164 art departments in accredited institutions of higher education.

White, J. M. (1979). Everyday life of the North American Indian. New York: Holmes \& Meier, Publishers, Inc.

Zimmerman, D. H., \& West, C. (1977). Sex roles, interruptions and silences in conversation. In Language and Sex: Difference and Dominance. N. Thorne and Henley, Eds. Rowley, MA: Newbury House. 
APPENDIX A

LETTER TO FACULTY 
Ms. Betty Owen

Department Head, English

Broward Community College

7200 Hollywood Blvd.

Pembroke Pines, FL 33024

Dear Ms. Owen:

I am beginning my work on a doctoral dissertation in the College of Education at Florida International

University. My plans include the study of the effect of the perception of visual artists in community college and university students. I would like to administer this study's questionnaires to the students in your department during the Spring or Summer Semester of 1992.

Participation in this study is voluntary, and the students will remain anonymous. All the responses will be coded. The students will be informed, after the completion of their questionnaires, about the purpose of this study. The results of the study will be available upon completion of this dissertation to any interested participants.

My dissertation committee, chaired by Dr. Joseph B. Cook, Professor of Education, Florida International

University, has approved this research proposal. I will be pleased to provide you with more information about this dissertation upon your request.

Thank you very much for your cooperation. I look forward to your response to this request.

Sincerely,

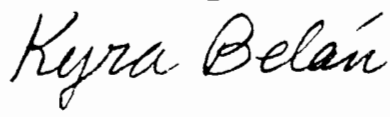

Kyra Belan

Doctoral Candidate

College of Education

Florida International University 
APPENDIX B

FACULTY INSTRUCTIONS 


\section{INSTRUCTIONS TO FACULTY OR THEIR DESIGNATED PERSON WHO WILL ADMINISTER THE QUESTIONNAIRE}

1. Before administering this questionnaire packet, notice that every packet is number 1 to 6 . Please make sure that the same amount of each type of packet, or as close as possible to the same amount, is distributed to the participating students.

2. The next step is to ask them to read the artist's biography and raise their hands as soon as they read it.

3. Follow immediately by showing the five slides of artist's works, giving each slide approximately 30 seconds on the screen.

4. After the slide viewing, the students will fill out the questionnaires in the order designated by their instructions.

5. You will need a slide projector and a screen in the classroom, and the ability to dim the lights just during the slide viewing time.

6. Please do not volunteer any information, known or assumed, about the purpose of this study during the testing procedure or after. Any assumptions about the nature of this study, whether correct or incorrect, may affect the final outcome of this study.

THANK YOU VERY MUCH FOR YOUR IMPORTANT

CONTRIBUTION TO THIS STUDY 
APPENDIX C

LETTER TO STUDENT 
Dear College Student:

I am presently conducting a study on college students' perceptions of visual artists. As a college student, you represent this study's population sample that is needed to accomplish the goals of this investigation.

This study is anonymous and your responses are voluntary. It is not necessary to state your name, and all responses will be coded. Full completion of the data is extremely important to the successful completion of this study.

The results of this study will be available to you upon request at the time of the completion of data analysis for this study. I may be contacted at the Art Department, Broward Community College, South Campus. study.

I appreciate very much your participation in this

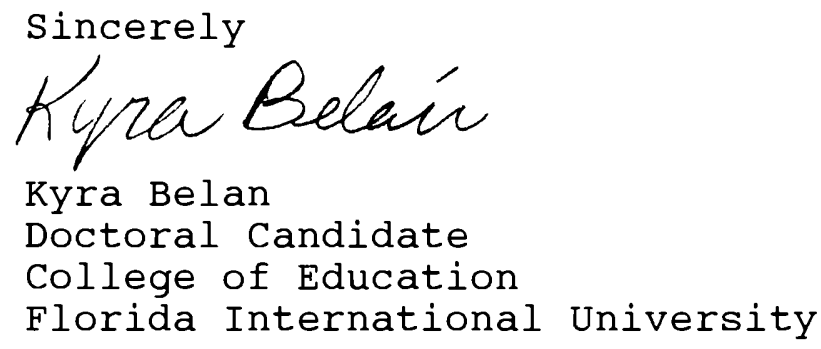


APPENDIX D

\section{INSTRUCTIONS}




\section{INSTRUCTIONS}

1. Please read artist's brief bio.

2. Please view five slides of this artist's paintings.

3. Please fill out Artist's Evaluation Questionnaire, circling the appropriate numbers (answers).

4. Please fill out the Demographic Questionnaire as follows: skip No. 1 ; fill out 2 as per instructions below; 3 to 9 circle correct answer.

5. Next, please fill out the Attitude Questionnaire as per instructions.

\section{PLEASE COMPLETE ALL QUESTIONNAIRES; YOUR COOPERATION IS HIGHLY APPRECIATED}

Your participation is anonymous.

The results will be available upon request (see letter) at the completion of this dissertational research.

THANK YOU FOR YOUR CONTRIBUTION TO THIS STUDY 
APPENDIX E

ARTIST'S BIOGRAPHICAL SKETCH 


\section{ARTIST'S BIOGRAPHICAL SKETCH}

The paintings that you will examine are by J. J. Stone, a woman who was born in Chicago in 1955, and is presently residing in Philadelphia. She teaches painting and sculpture at a local community college, and is also an adjunct faculty at a university. She likes to paint and exhibit her works. These works are typical of the production of this woman. 
APPENDIX F

ARTIST EVALUATION QUESTIONNAIRE 
1. In your personal opinion, how creative is this artist?
very poor creativity ............... 1
below average creativity ............ 2
slightly below average creativity ....... 3
average creativity ................ 4
slightly above average creativity ...... 5
above average creativity ............ 6
highly above average creativity ....... 7

2. Is this artist's work emotionally appealing to you?

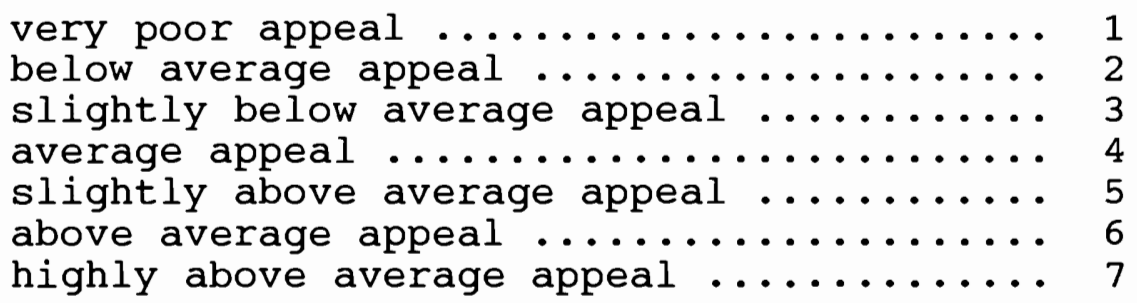

3. In your opinion, how competent is this artist in terms of the technique of painting?

very poor technique ............... 1

below average technique .............. 2

slightly below average technique ........ 3

average technique ................ 4

slightly above average technique ....... 5

above average technique ............. 6

highly above average technique ........ 7

4. These five paintings were purchased by the art in public places program. Please give your best estimate of the purchase price (value) of all five works.

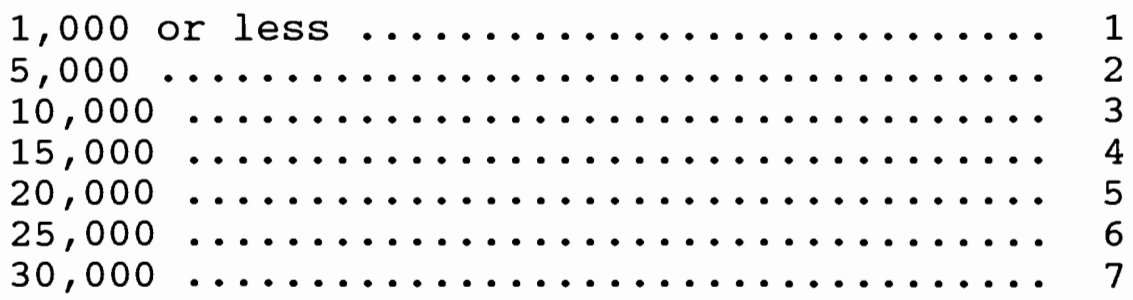

5. In your opinion, how does this artist impress you in terms of intelligence? 
very low intelligence $\ldots \ldots \ldots \ldots \ldots \ldots \ldots . \ldots \ldots$

below average intelligence ............. 2

slightly below average intelligence ..... 3

average intelligence ............. 4

slightly above average intelligence ..... 5

above average intelligence ........... 6

highly above average intelligence ...... 7

6. How gifted (possessing natural artistic ability) does this artist seem to be, according to your perception?

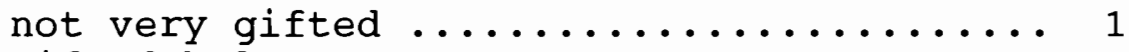

gifted below average .............. 2

gifted slightly below average ............ 3

gifted at average level ............ 4

gifted slightly above average level ..... 5

gifted above average level ........... 6

gifted way above average level ........ 7

7. Would you be willing to display this artist's works at your own home?

not particularly ................ 1 maybe willing to display ............. 2 willing to display, but not too interested 3 willing to display ............... 4 very willing to display ............ 5 very much willing to display .......... 6 absolutely enthusiastic about displaying . 7

8. How much do you like this artist, judging from the work seen?

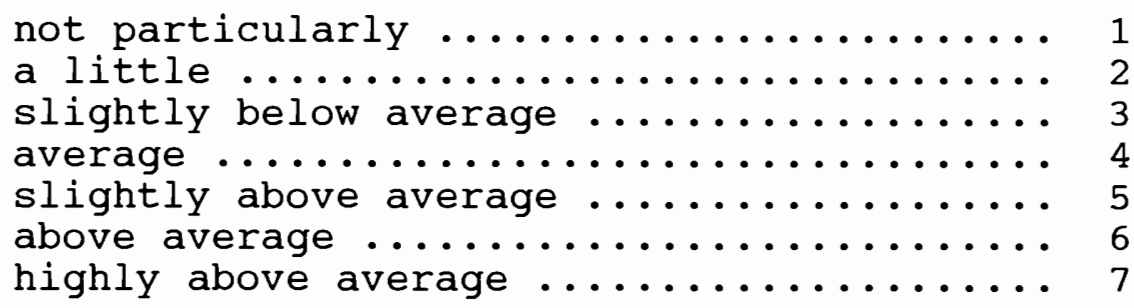

9. In your opinion, what kind of future success is this artist capable of achieving?

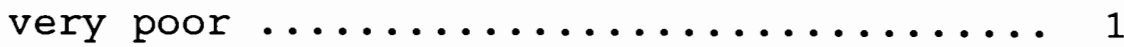

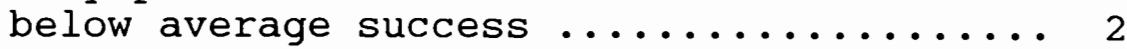

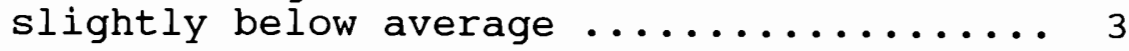

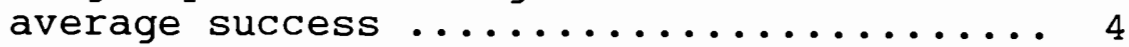

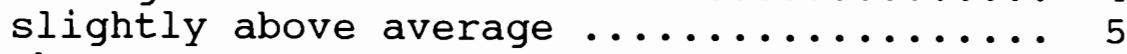

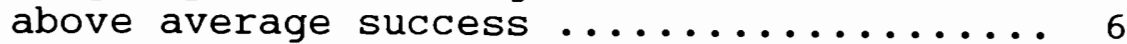
highly above average success .......... 7 
APPENDIX G

DEMOGRAPHIC QUESTIONNAIRE 
1. Case number (do not fill out)

2. State your date of birth

$\overline{\text { month }} \quad \overline{\mathrm{day}} \quad \overline{\text { year }}$

3. Sex

$\overline{\text { female }} \overline{\text { male }}$

4. Ethnic origin

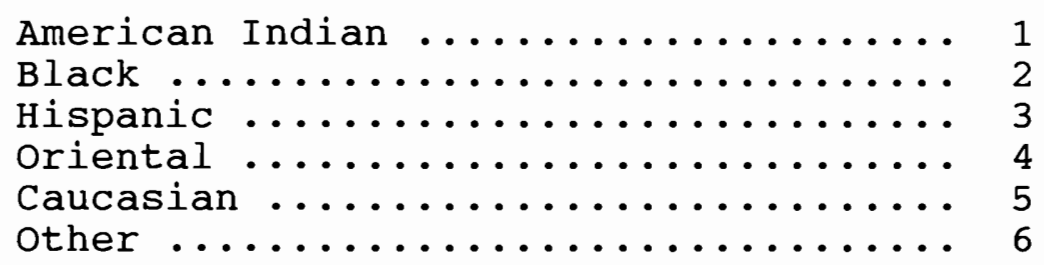

5. Do you have a high school diploma or a GED certificate?

Yes $\ldots \ldots \ldots \ldots \ldots \ldots \ldots \ldots \ldots \ldots \ldots \ldots$

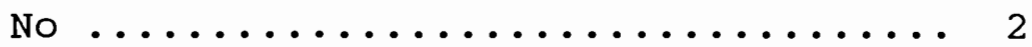

Do not know $\ldots \ldots \ldots \ldots \ldots \ldots \ldots \ldots$

6. How many semesters/years of college did you complete?

1 semester or less ............ 12

1 year ........................ 13

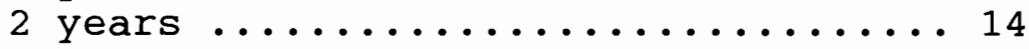

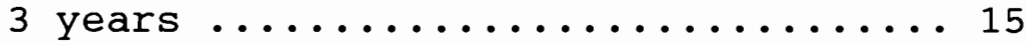

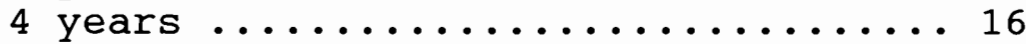

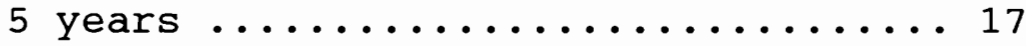

more than 5 years ............. 18

7. Do you have a college/university degree?

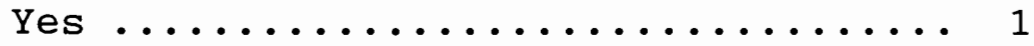

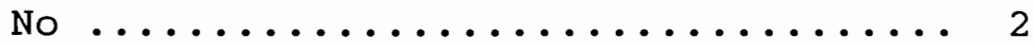

Do not know $\ldots \ldots \ldots \ldots \ldots \ldots \ldots \ldots$ 
8. If you answered yes to the previous question, what degree(s)?

Associate/community college ....... 2

Bachelor's ...................... 3

Graduate .................. 4

Do not know ................ 8

9. Are you employed?

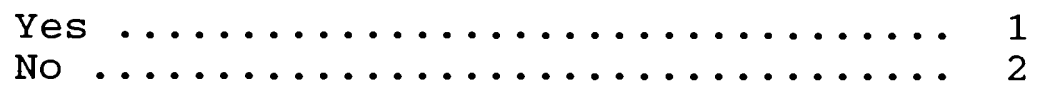

10. If yes, what is your total annual income?

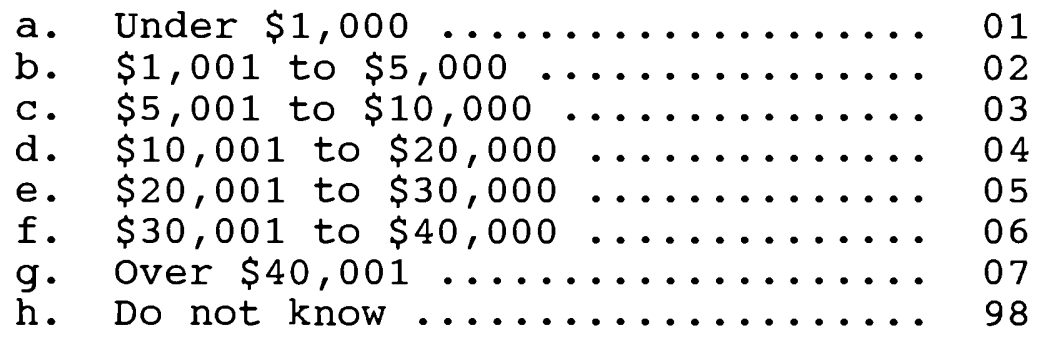

11. If not employed, what is your total family/guardian income?

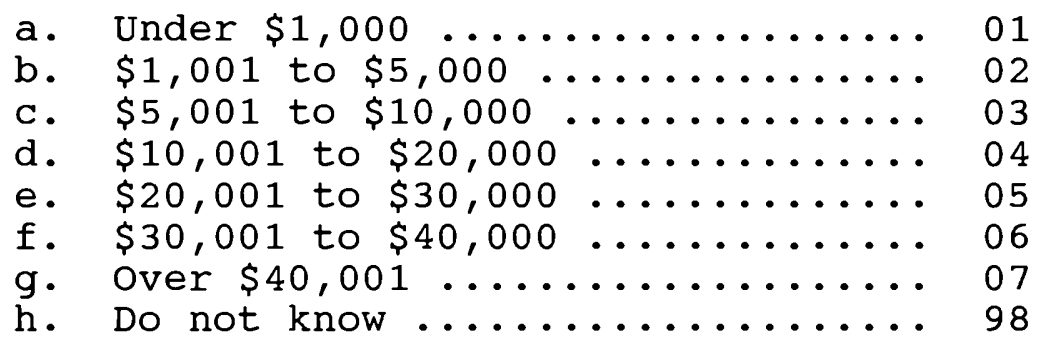

12. What is your present marital status?

Never married ................ 1

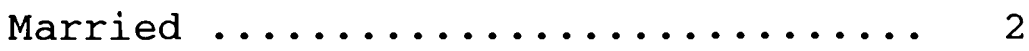

Divorced ....................... 3

Separated ................... 4

widowed ................... 5 
APPENDIX H

ATTITUDE QUESTIONNAIRE 
Instructions: Indicate on a scale of 1-7 how well each of the following characteristics describes you using the following scale: (1) never or almost never true; (2) usually not true; (3) sometimes not true; (4) occasionally true; (5) often true; (6) usually true; (7) always or almost always true:

- 1. self-reliant

2. yielding

3. helpful

_ 4. defends own beliefs

5. cheerful

- 6. moody

- 7. independent

- 8. shy

- 9. conscientious

10. athletic

_ 11. affectionate

12. theatrical

13. assertive

_ 14. flatterable

15. happy

_ 16. strong personality

_ 17. Loyal

18. unpredictable

19. forceful

20. feminine
21. reliable
22. analytical
23. sympathetic
24. jealous
25. has leadership
abilities
26. sensitive to the needs of others
27. truthful
28. willing to take
risks
29. understanding
30. secretive
31. makes decisions easily
32. compassionate
33. sincere
34. self-sufficient
35. eager to soothe hurt feelings
36. conceited
37. dominant
38. soft spoken
39. likeable
40. masculine

41. warm

42. solemn

43. willing to take a stand

44. tender

45. friendly

46. aggressive

47. gullible

48. inefficient

49. acts as a leader

50. adaptable

51. childlike

52. individualistic

53. does not use harsh language

54. unsystematic

55. competitive

56. Lives children

57. tactful

58. ambitious

59. gentle

60. conventional 